Document downloaded from:

http://hdl.handle.net/10251/103991

This paper must be cited as:

Payri, R.; Viera-Sotillo, JP.; Gopalakrishnan, V.; Szymkowicz, P. (2017). The effect of nozzle geometry over ignition delay and flame lift-off of reacting direct-injection sprays for three different fuels. Fuel. 199:76-90. doi:10.1016/j.fuel.2017.02.075



The final publication is available at

http://doi.org/10.1016/j.fuel.2017.02.075

Copyright Elsevier

Additional Information 


\title{
The effect of nozzle geometry over ignition delay and flame lift-off of reacting direct-injection sprays for three different fuels
}

\author{
Raul Payri ${ }^{\mathrm{a}, *}$, Juan P. Viera ${ }^{\mathrm{a}}$, Venkatesh Gopalakrishnan ${ }^{\mathrm{b}}$, Patrick G. \\ Szymkowicz ${ }^{\mathrm{b}}$ \\ ${ }^{a}$ CMT-Motores Térmicos, Universitat Politècnica de Valencia, Camino de Vera s/n, \\ 46022 Valencia, Spain \\ ${ }^{b}$ Diesel Engine Systems Group, Propulsion Systems Research Lab, GM R\&D Center, \\ $M C$ : 480-106-252, 30500 Mound Rd., Warren, MI 48090-905, USA
}

\begin{abstract}
1 The influence of internal nozzle flow characteristics over ignition delay, and flame lift-off of reacting direct-injection sprays is studied experimentally for three fuels using two different nozzle geometries. This is a continuation of previous work by the authors, where, evaporative and non-evaporative, isothermal spray developments were studied experimentally for the same nozzle geometries and fuels. Current study reports the ignition delay through Schlieren technique, and flame lift-off length through $\mathrm{OH}^{*}$ chemiluminescence visualization. The nozzle geometries consist of a conical nozzle and a cylindrical nozzle with $8.6 \%$ larger outlet diameter when compared to the conical nozzle. The three fuels considered are n-heptane, n-dodecane and a three-component surrogate to better represent the physical and chemical properties of diesel fuel. Reacting spray is found to penetrate faster than non-reacting spray due to combustion induced acceleration after ignition. Higher oxygen concentration, and ambient temperature enhance the reactivity leading to higher spray tip penetration. Injection pressure does not affect

\footnotetext{
${ }^{*}$ Corresponding author

Email address: rpayri@mot.upv.es (Raul Payri)

${ }^{1}$ Raul Payri, Juan P. Viera, Venkatesh Gopalakrishnan, Patrick G. Szymkowicz, The
} effect of nozzle geometry over ignition delay and flame lift-off of reacting direct-injection sprays for three different fuels, Fuel, Volume 199, 1 July 2017, Pages 76-90, ISSN 00162361, https://doi.org/10.1016/j.fuel.2017.02.075.
\end{abstract}


the reactivity significantly and hence, influences spray penetration through momentum - similar to a non-reacting spray. Both ignition delay and lift-off length are found to be shortest and longest for n-dodecane and n-heptane, respectively, while the surrogate fuel falls in-between the two pure component fuels. Both ignition delay and lift-off length are found to decrease with increase in oxygen concentration, ambient temperature, and density. The cylindrical nozzle, in spite of shorter lift-off length is found to have longer ignition delay, when compared to the conical nozzle. This could be due to better atomization leading to larger spread angle and evaporative cooling from the cylindrical nozzle compared to a conical nozzle. The longer ignition delay also leads to leaner equivalence ratios at the time of ignition.

Keywords: Reactive spray development, surrogate fuels, lift-off length, vapor penetration, ignition delay

\begin{tabular}{|llll|}
\hline \multicolumn{2}{|l}{ Nomenclature } & & \\
$\rho$ & Ambient density & CFD & Computational fluid dynamics \\
$C_{p, l i q}$ & $\begin{array}{l}\text { Liquid phase constant pressure } \\
\text { specific heat capacity }\end{array}$ & ECN & Engine Combustion Network \\
$d_{o}$ & Orifice nominal diameter & FOV & Field of view \\
$h_{v a p}$ & Specific enthalpy of vaporization & ID & Ignition delay \\
$P_{r}$ & Rail pressure & LOL & Lift-off length \\
$T_{a}$ & Ambient temperature & PAH & Polycyclic aromatic hydrocarbon \\
$T_{b}$ & Boiling temperature & SoCF & Start of cool flames \\
$k 0$ & Cylindrical nozzle & SOI & Start of injection \\
$k 15$ & Conical nozzle & SSI & Second stage ignition \\
& & & \\
\hline
\end{tabular}

\section{Introduction}

2 Fuel injection, mixing, evaporation and combustion processes are the key 3 to reduce pollutant formation and improve efficiency of direct injection diesel 
engines [1]. To this end, engine research and development groups have been trying for decades to better understand and describe the fundamentals of these processes, including alternative fuels and combustion strategies [2-5]. Fuel sprays, being primarily characterized by physically complex phenomena and intrinsically stochastic behavior, are remarkably challenging to comprehend by engine and combustion researchers. Over the last three decades, experimental researchers have studied fuel sprays thoroughly in search for a better understanding of these phenomena and also for supporting data that enables validation of detailed numerical models [6]. Among all challenges presented by the physics of fuel sprays injected in-cylinder, the effect of nozzle geometry on the formation, mixing and combustion of the diesel spray is still of interest to the research community and the automotive industry [7-10]. Even though it has been studied before, the full extent of the nozzle geometry effects over a wide span of operating conditions (including fuels) and response variables is not yet fully understood. For instance, Ganippa et al. [11] presented results claiming that nozzle flow characteristics have negligible influence over the spray formation and that momentum is the only controlling variable for mixing. Opposite to this study, several authors show that the flow inside the nozzle influences the near-nozzle region of the spray in terms of liquid-phase break-up, liquid length, and spray angle [12, 13]. Other studies also evidence the effects of nozzle flow characteristics over the macroscopic spray $[14,15]$. This contrast, along with the remaining uncertainty on the effect of nozzle geometry on entrainment, combustion, and pollutant formation, leaves room for fundamental questions on the subject.

These fundamental questions could be addressed from the information provided by computational fluid dynamic (CFD) models, which output a large amount of temporal and spatial data that the experimental approach is unable to acquire [6]. Current models still require high-fidelity experimental data for validation and accurate bounding of the problem. Majority of current spray models employ initial and boundary conditions at the nozzle exit as an indirect coupling to the flow inside the nozzle $[15,16]$. Such methods often dampen or lose smaller scale nozzle flow characteristics, and also present numerical issues such as different time-step lengths for each model to be coupled. Hence, the computed spray development using the indirect coupling is mainly dictated by momentum, aerodynamics, and mixing. Recently, a few authors have published computational models that employ a full grid comprising the nozzle internal geometry and the spray [17-19]. It is important to point out that the work presented by Desantes et al. [19] and 
Xue et al. [18] have benefited significantly by the considerable size and good quality of the Engine Combustion Network (ECN) open database and efforts (http://www.sandia.gov/ecn/, [20]), which allowed access to very high resolution tomographies of the internal nozzle geometry, along with extensive experimental data from different institutions around the world. However, fuel properties were still out of the scope of the ECN and questions raised about the interaction between nozzle geometry and fuel characteristics over the reactive spray are still not fully understood.

CFD models require minimal uncertainties in physical and chemical fuel properties. The development of surrogate fuels is one way to achieve this while providing detailed chemical kinetic mechanisms [21-23] further reduced to computable sizes $[22,24]$ that can be employed in a fully reactive spray model. Surrogate fuels are often carefully tailored to mimic the behavior of real diesel fuel over the diagnostic being performed [22, 25, 26]. For some years, the surrogate of choice for diesel fuel has been a single-component species n-heptane. There have been two important reasons for this choice. First, n-heptane has a Cetane number of 56 that is reasonably close to the Cetane number of common diesel fuel, so its ignition is similar to that of diesel fuel which is convenient for ignition or heat release studies [15, 20, 27]. In addition, a detailed kinetic reaction mechanism for n-heptane was published by Curran et al. [21] in 1998 with all of the detail required to carry out thorough combustion studies. Recently, it has become apparent that n-heptane is not sufficient as a diesel surrogate, for instance, Idicheria and Pickett [28] showed that the n-heptane flame produces considerably less soot than a \#2 diesel flame at similar conditions, and the soot distribution within the flame was also found to be quite different. Therefore, richer surrogates containing aromatics and other species that are important components in diesel fuels must also be represented in the surrogate selected for this study. In the present paper, three surrogate fuels are employed, n-heptane as the classical diesel substitute, n-dodecane that has been widely accepted as a diesel substitute in recent years and it was decided as reference fuel for the ECN $[20,29]$ and finally a multi-component diesel surrogate consisting of ntetradecane (0.5), n-decane (0.25) and $\alpha$-methylnaphthalene (0.25) is utilized $[30,31]$. Numbers in parentheses represent mass fractions.

This study is a contribution to the current understanding on the effects of nozzle geometry and fuel type over combusting sprays, in terms of second stage ignition (SSI) delay and lift-off length. The study follows up on three previous works which analyze the effect of nozzle geometry over the liquid 
1

iso-thermal non-evaporative spray formation [32], the effect of nozzle geometry combined with different fuels on the hydraulic performance and liquid isothermal non-evaporative spray formation [30], and the same nozzles and fuels on evaporative conditions [31]. In this work, all experiments were also performed for the same nozzle geometries (cylindrical and conical convergent) and fuel types. The experimental campaign consisted of characterizing the SSI delay through the Schlieren technique [20, 29, 33-36], and the lift-off length (LOL) through $\mathrm{OH}^{*}$ chemiluminescence visualization $[29,33,34,36-$ 38], in high temperature/high pressure chamber conditions, covering a wide range of parametric variations that include temperature, density and oxygen concentration sweeps. With these experiments, two main goals are pursued: first, to evaluate the influence of nozzle flow characteristics over the basic combustion phenomena supporting experimental data for different fuels and second, an effort is made in obtaining a large database of quality data useful for CFD model validations with different fuels. State-of-the-art experimental techniques, facilities and equipment were employed in order to ensure highest quality of data acquired and reported. All experimental data presented in this paper is available for download at http://www.cmt.upv.es/DD01. aspx.

\section{Materials and methods}

\subsection{Hardware}

\subsubsection{The high temperature and high pressure test rig}

All visualization experiments were performed in a constant pressure-flow test chamber, capable of mimicking the in-cylinder thermo-dynamic conditions of a diesel engine during the fuel injection. This test rig features the unique capability of obtaining nearly quiescent and, compared to other facilities such as constant volume chambers [39], steady thermodynamic conditions within the chamber. This is particularly useful for extensive experimental campaigns with parametric variations of thermodynamic test conditions. The steady, quiescent test conditions provide a high test repetition rate - also reducing the effective test time for a given set of test conditions - and enhance the shot-to-shot precision of the tests performed.

A set of electrical resistors located inside the inlet pipe that leads into the chamber heat incoming gas. This arrangement is capable of reaching and maintaining a maximum temperature and pressure of $1000 \mathrm{~K}$ and $15 \mathrm{MPa}$ respectively, in the test chamber. The chamber has three large optical access windows $-128 \mathrm{~mm}$ in diameter - placed orthogonally, providing full optical 
1 3 40].

access to the injection event. A description, photo and schematic of the installation can be found in works previously published by the authors [36,

\subsubsection{The fuel injection system}

A common-rail injection system consisting of a high pressure pump and a conventional rail with an electronic pressure regulator is used [41, 42]. This system can generate relatively high rail pressures of up to $220 \mathrm{MPa}$ and maintain it at the set value while injecting fuel. The injector body temperature is controlled using a special injector holder designed to have coolant flowing in direct contact with the injector body. The temperature of the coolant is adjusted in function of the discharge chamber gas temperature and density, to guarantee a constant sac inner wall temperature of approximately $110^{\circ} \mathrm{C}[29,43]$. The injector's return line was pressurized to $0.6 \mathrm{MPa}$ as required by the injectors to work properly. The entire fuel injection system is electronically controlled and all the settings are introduced digitally.

\subsubsection{Nozzles}

All experiments were performed for two different nozzles, mounted on two independent injector bodies. Table 1 summarizes the injectors utilized and their nominal nozzle geometries. The injectors are piezo-electrically actuated Bosch injectors. The two nozzles are micro-sac type single-hole nozzles, with different conicity but equal hydro grinding $(13.5 \%$ each) and nominal flow rate $\left(124 \mathrm{~cm}^{3} / \mathrm{min} / 10 \mathrm{MPa}\right.$ each). Note that Table 1 includes reference symbol and color columns which indicates the symbols and/or colors that will be used to distinguish nozzles in the results section.

Table 1: Injector hardware utilized and nominal nozzle geometries.

\begin{tabular}{cccccc}
\hline Nozzle ref. & Nozz. type & $d_{o}[\mu m]$ & k-factor & Ref. symbol & Ref. color \\
\hline k0 & micro-sac & 151 & 0 & $\diamond$ & purple \\
k15 & micro-sac & 138 & 1.5 & $\circ$ & green \\
\hline
\end{tabular}

\subsubsection{Fuels}

All experiments were also performed for three different fuels. The first fuel selected is n-heptane. As stated in the section 1, n-heptane has long been 
utilized as a diesel surrogate to mimic diesel fuels in ignition and/or heat release studies [21, 24, 27, 44, 45]. The second fuel selected is n-dodecane, which features similar carbon content and boiling characteristics to those of diesel fuels, so it is expected to better mimic the mixing behavior of diesel fuels. This is one of the reasons n-dodecane was also selected as the primary fuel of study for the main ECN campaign [20], and it has been extensively characterized in the complete spectrum of experimental diagnostics and numerical simulations performed by the group. However, n-dodecane is not expected to be an adequate surrogate for ignition-related behavior, because of its Cetane number (approx. 88). Last, a multi-component diesel surrogate consisting of n-tetradecane (0.5), n-decane (0.25) and $\alpha$-methylnaphthalene $(0.25)$ is utilized. Numbers in parentheses represent mass fractions. This surrogate - from this point forward simply referred to as "Surrogate" - is expected to better mimic the soot-related behavior of real diesel fuel due to the PAH content and $\mathrm{C} / \mathrm{H}$ ratio being closer to that of real diesel fuel. The short ignition delays expected due to the large n-tetradecane and n-decane contents (with Cetane numbers close to 96 and 77 respectively) are, at the same time, delayed by the the $\alpha$-methylnaphthalene content. Fuel properties relevant to this study are summarized in Table 2.

Table 2: Fuels utilized and their properties at $298 \mathrm{~K}$ and $101 \mathrm{kPa}$. Except for the Surrogate fuel, all properties were extracted from the NIST Chemistry WebBook [46]. For the Surrogate fuel, density, viscosity and surface tension were measured as per ASTM D1298, ASTM D445 and UNE EN 14370 respectively.

\begin{tabular}{lcccc}
\hline Property & Units & n-Heptane & n-Dodecane & Surrogate \\
\hline Density & $\mathrm{kg} / \mathrm{m}^{3}$ & 679.7 & 745.8 & 802.1 \\
Viscosity & $\mathrm{Pa} \mathrm{s}$ & $5.59 \mathrm{e}-4$ & $1.36 \mathrm{e}-3$ & $1.61 \mathrm{e}-3$ \\
Surface tension & $\mathrm{N} / \mathrm{m}$ & 0.020 & 0.025 & 0.026 \\
Boiling point & $\mathrm{K}$ & 372 & 489 & 450 to 520 \\
$C_{p, l i q}$ & $\mathrm{~J} / \mathrm{kg} / \mathrm{K}$ & 2234 & 2212 & Tab. 3 \\
$h_{\text {vap }}$ & $\mathrm{kJ} / \mathrm{kg}$ & 359 & 358 & Tab. 3 \\
\hline Ref. color & - & cyan & blue & magenta \\
\hline
\end{tabular}

The Surrogate distillation curve was presented by the authors in [31]. This Surrogate starts boiling near $450 \mathrm{~K}$, which corresponds to the boiling point of n-decane. On the other hand, it is completely evaporated near $520 \mathrm{~K}$ which corresponds to the boiling point of n-tetradecane, which comprises half 
Fuel, Volume 199, 1 July 2017, Pages 76-90

Table 3: Components of the Surrogate fuel and their properties at $298 \mathrm{~K}$ and $101 \mathrm{kPa}$. All properties were extracted from the NIST Chemistry WebBook [46].

\begin{tabular}{lcccc}
\hline Property & Units & n-Tetradecane & n-Decane & $\alpha$-methylnaphthalene \\
\hline Boiling point & $\mathrm{K}$ & 523 & 447 & 515 \\
$C_{p, l i q}$ & $\mathrm{~J} / \mathrm{kg} / \mathrm{K}$ & 2208 & 2192 & 1578 \\
$h_{\text {vap }}$ & $\mathrm{kJ} / \mathrm{kg}$ & 361 & 361 & 415 \\
\hline
\end{tabular}

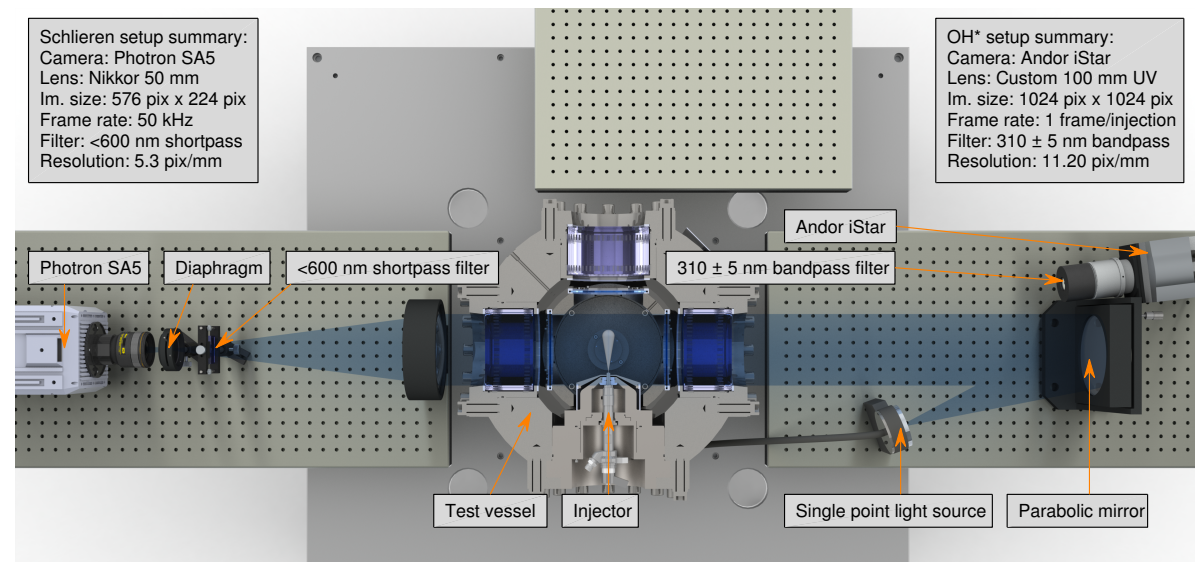

Figure 1: Plan view of the optical setup.

of the mass of the Surrogate fuel. Note also that n-heptane features a boiling point considerably lower than the boiling range of the Surrogate, which at the same time contains the boiling point of n-dodecane.

\subsection{Reactive spray visualization}

\subsubsection{Optical setup}

The optical setup, shown in Figure 1, consisted of two separate cameras and optical arrangements for the visualization of the reactive spray development and lift-off length. Note that both cameras recorded all injection events simultaneously.

Schlieren imaging has been successfully employed several times to identify refractive index gradients in transparent mediums. For vaporizing diesel sprays, this technique is able to capture the line-of-sight boundary between vaporized fuel and ambient gases, as there is an appreciable difference in refractive indices between these $[6,20,47]$. Since the rays of light are collimated 
into a cylindrical beam, small deflections due to refractive index gradients are rendered in the image as shades. In this study, the vapor spray was visualized through a single-pass Schlieren setup [6,31], which is often applied to axi-symmetrical single hole nozzles. Multi-hole injectors require a two-pass setup and a high temperature mirror as explained by Payri et al. [40, 48]. The final setup is very similar to the setups employed for the CMT experiments in $[20,33,36,49]$ and exactly the same to the setup utilized by Payri et al. [31] in their inert sprays study of the same nozzles and fuels. The camera was a Photron SA5, sampling images of 576 pix $\times 224$ pix at $50 \mathrm{kHz}$ with a spatial resolution of $5.3 \mathrm{pix} / \mathrm{mm}$. This produced a field of view (FOV) along the spray axis of $108 \mathrm{~mm}$, and considering window limits and nozzle location, the maximum penetration length measurable was $96 \mathrm{~mm}$. The exposure time was set to $2.28 \mu \mathrm{s}$.

The lift-off length (LOL), defined as the axial distance measure from the orifice outlet at which the flame stabilizes during steady state combustion, was measured capturing the signal from $\mathrm{OH}^{*}$ chemiluminescence following the ECN standard methodology $[33,36,37]$. An ICCD camera (Andor iStar) fitted with a custom $100 \mathrm{~mm} \mathrm{f} / 2.8 \mathrm{UV}$ lens and a $310 \mathrm{~nm} \pm 5 \mathrm{~nm}$ interferometric filter was used to acquire the chemiluminescence signal. Since this signal is weak, the intensifier of the camera sensor was gated during the steady region of the injection - $2.3 \mathrm{~ms}$ to $4.8 \mathrm{~ms}$ after start of energizing (SOE) - to obtain an on-chip time-averaged signal, minimizing the effect of local turbulent flame behavior. Note that this camera had to be inclined slightly off axis so not to block the collimated Schlieren beam. However, the angle is small at $7^{\circ}$, and the possible effects are accounted for by properly correcting the images. The camera sampled one image per injection event, of 1024 pix $\times 1024$ pix with a spatial resolution of $11.2 \mathrm{pix} / \mathrm{mm}$. This produced a FOV along the spray axis of approximately $90 \mathrm{~mm}$. Further details of the processing algorithm for the LOL estimations can be found in $[33,36]$.

\subsubsection{Schlieren image processing}

Each image is processed using an algorithm that detects the spray boundary and computes its associated properties. The program - similar to what the authors employed in their previous study of the same nozzles and fuels at inert ambient conditions [31] - consists of two extensively used approaches for the processing of these type of images. Two binarized images are obtained from two different criteria and then merged to maximize sensitivity. The first algorithm was originally developed at Sandia Na- 
tional Laboratories (SNL) and is available for download on the ECN website (http://www.sandia.gov/ecn/). The routine detects temporal changes in pixel-wise intensities by taking the temporal derivative of a series of images. This produces a 2D map where pixels with higher intensity represent pixels that are changing their digital values in time. The temporal nature of this algorithm makes it robust to variations between optical setups, and makes it very strong for transparent spray images, for example, of very dilute sprays, low ambient density conditions, light fuels, etc. On the other hand, it does not work properly for spray images with relatively constant intensity levels, for example: images of non-evaporative sprays, diaphragm-cut Schlieren vapor sprays (which are often very dark), combustion-saturated sprays, etc. In these situations, spray tip penetration is still captured correctly while the full spray boundary is not. Therefore, an additional intensity-sensitive algorithm was adapted, explained in detail by Payri et al. [40], enhanced with the dynamic background correction detailed by Benajes et al. [33] and Payri et al. [36]. The two binary maps obtained from each algorithm are combined into a single binary image from which the contour is extracted. This approach maximizes sensitivity since it takes advantage of the robustness of the SNL algorithm for the spray tip region - and dilute regions or sprays - but at the same time allows for good contour detection in the near nozzle region, where the liquid core often generates a very dark image.

The algorithm then extracts macroscopic characteristics from the detected contours. Spray tip penetration is calculated as the distance between the outlet orifice and the furthest point in the detected boundary. The estimation of SSI delay comes from the signal obtained by computing the sum of the pixel-wise intensities within this boundary (from this point forward referred to as total intensity). This summation is done over the inverted spray image, so an increase in the total value indicates a darker and/or larger spray. The resulting signal, and its derivative in time (from this point forward referred to as total intensity increment), present unique-consistent features that allow for reliable estimation of the SSI, as thoroughly detailed by Benajes et al. [33], Payri et al. [36].

\subsubsection{Test plan}

The test plan is presented in Table 4, it is centered on ECN Spray A boundary conditions [20], with parametric variations around these. Since the time available for experiments was limited, note that the test matrix does not comprise every combination of the studied variables, but sweeps 
Table 4: Spray visualization test plan, centered on ECN Spray A boundary conditions [20].

\begin{tabular}{lll}
\hline Parameter & Value-Type & Units \\
\hline Ambient density & 22.8 & $\mathrm{~kg} / \mathrm{m}^{3}$ \\
Ambient temp. & $800,900,970$ & $\mathrm{~K}$ \\
Rail pressure & $60,90,150,200$ & $\mathrm{MPa}$ \\
Oxygen conc. & 21 & $\%$ \\
No. of points & $12 /$ nozzle/fuel & \\
\hline Ambient density & 22.8 & $\mathrm{~kg} / \mathrm{m}^{3}$ \\
Ambient temp. & $800,900,970$ & $\mathrm{~K}$ \\
Rail pressure & $60,90,150$ & $\mathrm{MPa}$ \\
Oxygen conc. & 15 & $\%$ \\
No. of points & $9 / \mathrm{nozzle} /$ fuel & \\
\hline Ambient density & $15.2,30.4$ & $\mathrm{~kg} / \mathrm{m}^{3}$ \\
Ambient temp. & 900 & $\mathrm{~K}$ \\
Rail pressure & $60,90,150$ & $\mathrm{MPa}$ \\
Oxygen conc. & 21 & $\%$ \\
No. of points & $6 /$ nozzle/fuel & \\
\hline Total points & $27 /$ nozzle/fuel & \\
\hline
\end{tabular}


of certain resolutions depending on the interest of each variable. Table 4 is sub-divided into these three groups of points for easier visualization of the test plan. For all conditions the energizing time was fixed at $2.5 \mathrm{~ms}$. All test points were performed for the two nozzles and three fuels, comprising a total of 162 test points in the high temperature/high pressure test rig. Note that all experimental results presented in this manuscript are available for download at: http://www.cmt.upv.es/DD01.aspx.

\section{Results and discussion}

\subsection{Reactive spray development}

Figure 2 presents a sequence of Schlieren images of two independent injection events for two different fuels. This sequence demonstrates the typical behavior of reactive diesel-type sprays: liquid fuel is injected into a hot ambient gas, the jet velocity and ambient density shear and atomize the liquid core, the spray entrains the surrounding hot gas which transfers energy to the liquid fuel and, downstream, liquid fuel eventually evaporates completely [31]. Note that a similar figure was presented by Payri et al. [31] for inert sprays, showing simultaneous contours for the liquid and vapor phases. Once the reactive spray reaches ignitable fuel mixture fractions, ignition and high temperature combustion take place. The reactive spray continues to penetrate, still exchanging momentum with the ambient gas and progressively slowing down. At the same time, the flame stabilizes in the upstream region at the LOL (see the last images shown for the n-dodecane spray). In these Schlieren images, the first stage of the ignition process is appreciable as a brief disappearance of the spray, followed by a sudden expansion and darkening, which corresponds to the second stage ignition (SSI, [50]) as explained by Benajes et al. [33] and Payri et al. [36, 49]. In the particular case presented in Figure 2, note how the n-dodecane spray (right column) starts the SSI earlier than the n-heptane spray — 524 us and 736 us respectively - which is expected, since n-dodecane is a heavier $n$-alkane with longer chain, making it more reactive. This difference in ignition delay (ID)causes differences in the corresponding spray tip penetrations, making the n-dodecane spray penetrate further. These findings will be analyzed in detail in the following sections. 



Figure 2: Time sequence of Schlieren images of two injection events of n-heptane and n-dodecane sprays. Images have been trimmed both in the radial and axial directions from their original size, for better fit in this figure. The contours detected are plotted to scale over the original Schlieren images. In this case, the nozzle is $k 15$, rail pressure is $150 \mathrm{MPa}$, ambient density is $15.2 \mathrm{~kg} / \mathrm{m}^{3}$, ambient temperature is $900 \mathrm{~K}$ and the oxygen concentration is $21 \%$. 


\subsection{Reactive spray tip penetration}

The effect of reactivity on spray tip penetration for three fuels is presented in Figures 3 and 4. Mixture reactivity is controlled by the oxygen concentration in the chamber, ambient temperature and fuel properties. In Figure $3,0 \%$ oxygen concentration corresponds to the non-reacting spray studied previously by the authors [31] while $21 \%$ oxygen concentration corresponds to highest reactivity spray, in terms of oxygen concentration. All three sprays penetrate at the same rate up to a certain time, after which, the penetration curve of the spray with higher reactivity (or oxygen concentration) starts to deviate more and penetrate faster. Once ignition takes place the spray tip accelerates due to the sudden expansion, which results in a faster spray tip penetration rate in comparison to the inert case. The faster ignition with higher oxygen concentration translates to higher spray tip penetration, as Pastor et al. [51] observed for a set of fuels with different reactivities. Figure 3 shows that, for all three fuels, higher oxygen concentration leads to earlier spray acceleration or deviation from the non-reacting case.

A similar situation can occur for different ambient temperatures. It is known that ambient temperature is not a determinant variable for evaporating, non-reactive spray development if the ambient density is matched $[31,40]$. Under reactive conditions however, ambient temperature plays an important role in all the chemical reactions prior to the SSI, and this could result in different spray penetration rates, as Figure 4 illustrates. Higher ambient temperatures lead to higher reactivity, shorter ignition delays and thus higher spray tip penetration. The ignition delay does not change significantly above $900 \mathrm{~K}$ and hence, when the temperature changes from $900 \mathrm{~K}$ to $970 \mathrm{~K}$ the spray penetration does not deviate as much as when the temperature is changed from $800 \mathrm{~K}$ to $900 \mathrm{~K}[23,24]$.

Figure 5 presents the effect of injection pressure on reactive spray tip penetrations. The effect of the injection pressure for non-reacting sprays is clear from the literature [30,31]. Increasing injection pressure increases spray momentum and thus, the spray tip penetration rate. As will be shown in section 3.4.2, injection pressure does not significantly influence the spray reactivity and ignition delay. Hence, the effect of rail pressure for reacting sprays is very similar to that of a non-reacting spray. The three different fuels show appreciable difference in reactivity and ignition delay and hence, a noticeable effect on spray penetration can be observed. The n-dodecane sprays penetrate faster earlier, followed by the Surrogate sprays, and n-heptane. 


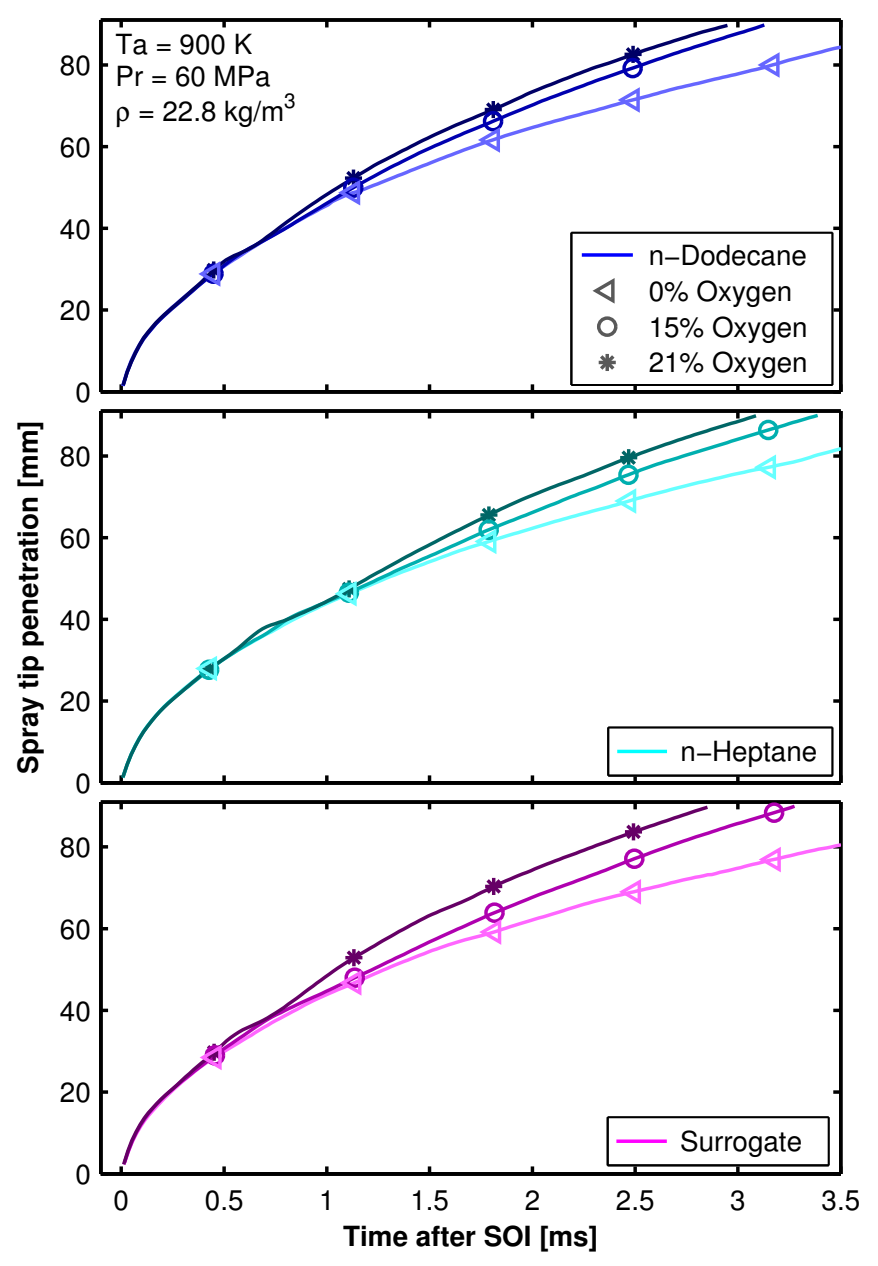

Figure 3: Spray tip penetration for all fuels at different oxygen concentrations. In this case, the nozzle is $k 15$, rail pressure is $60 \mathrm{MPa}$, ambient density is $22.8 \mathrm{~kg} / \mathrm{m}^{3}$ and ambient temperature is $900 \mathrm{~K}$. Note that inert spray results correspond to a previous study from the authors [31]. 


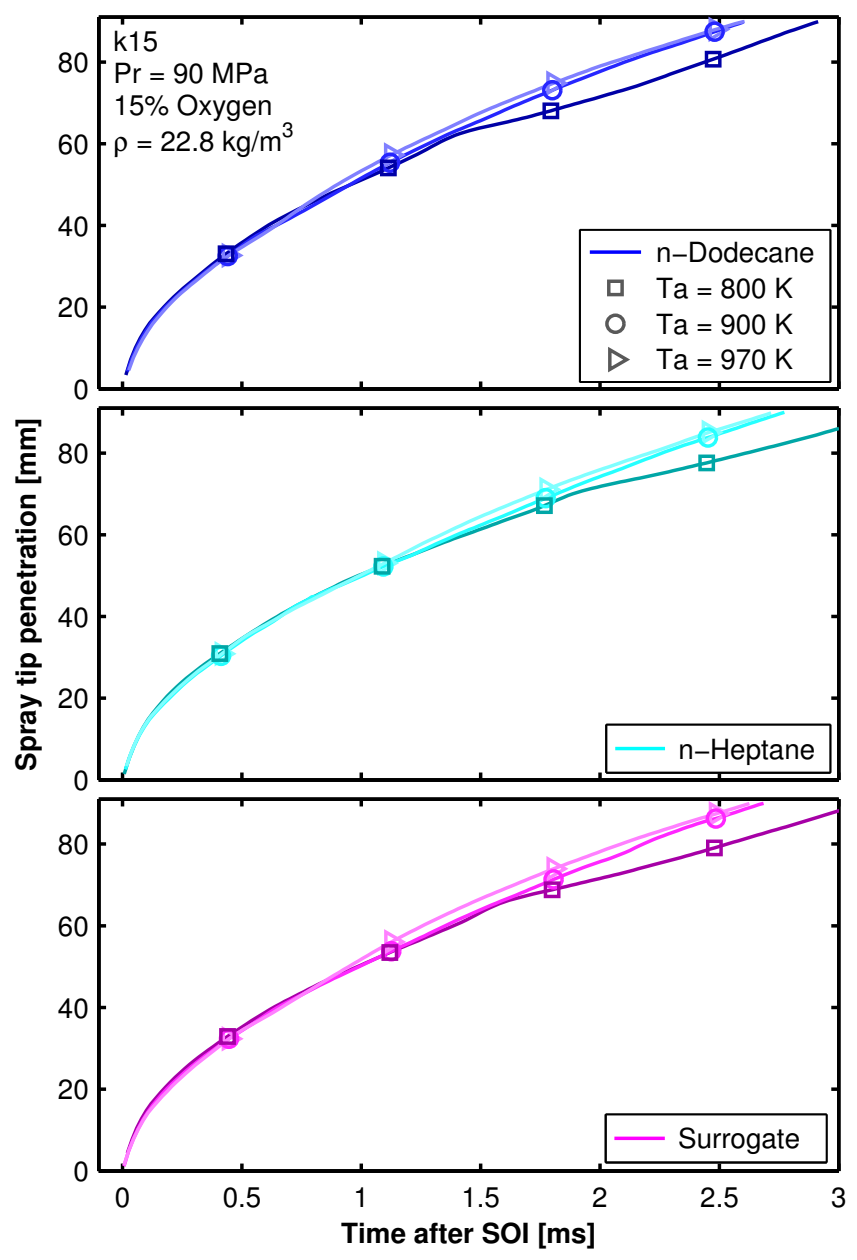

Figure 4: Spray tip penetration for all fuels at different ambient temperatures. In this case, the nozzle is $k 15$, rail pressure is $90 \mathrm{MPa}$, ambient density is $22.8 \mathrm{~kg} / \mathrm{m}^{3}$ and oxygen concentration is $15 \%$. 


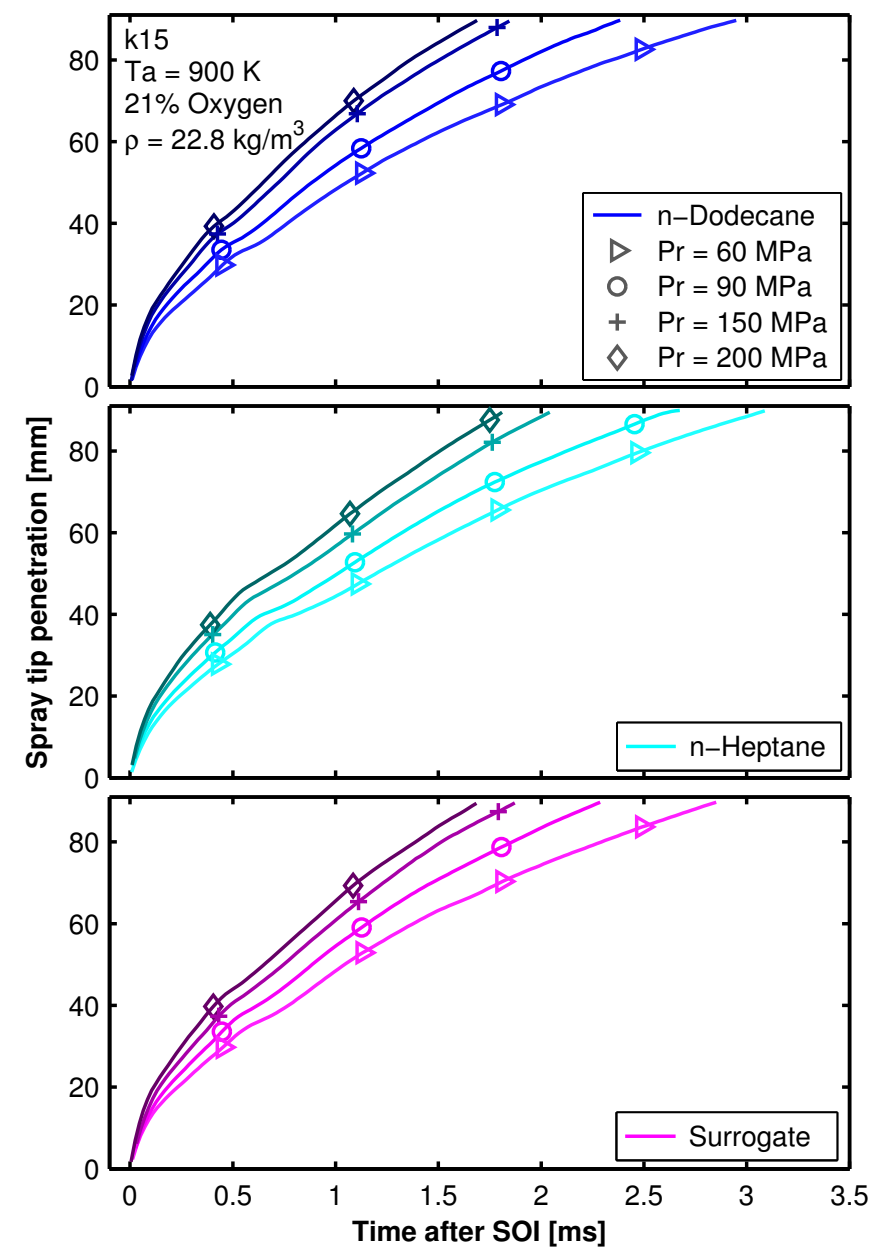

Figure 5: Spray tip penetration for all fuels at different rail pressures. In this case, the nozzle is $k 15$, ambient temperature is $900 \mathrm{~K}$, ambient density is $22.8 \mathrm{~kg} / \mathrm{m}^{3}$ and oxygen concentration is $21 \%$. 


\subsection{Lift-off length}

Before presenting results obtained it is interesting to review the parameters affecting LOL as known from the literature. These are fuel composition, ambient temperature, ambient density, ambient oxygen concentration, injection pressure and nozzle geometry $[33,36,37,51]$. Because of the large data base of the present investigation, select cases will be presented to illustrate the effect of each variable studied.

\subsection{1. $O H^{*}$ chemiluminescence signals}

Figure 6 depicts a comparison of the reactive sprays produced by the two nozzles at particular test conditions. The top and middle parts of Figure 6 show ensemble-average $\mathrm{OH}^{*}$ chemiluminescence images while the bottom part plots column-wise intensity maximums of the images. The results at these test conditions show that nozzle $k 0$ produces a spray with shorter LOL when compared to nozzle $k 15$, even though its diameter is slightly larger $[15$, 37]. Signals presented at the bottom part of Figure 6 illustrate very similar behaviors between the two nozzles in terms of flame shape and intensity levels. The flame produced by nozzle $k 15$ shows slightly higher intensity levels downstream which, qualitatively, could be attributed to a more fuelrich flame, and thus, soot. Payri et al. [30,31, 32] observed that, when compared to the cylindrical nozzle $k 0$, the conical nozzle $k 15$ features smaller spreading angles, so it would be expected for this nozzle to produce a more soot-promoting flame.

Figure 7 depicts a comparison of the reactive sprays produced by the three fuels at particular test conditions. Contrary to the comparison shown in Figure 6, images and profiles depicted in Figure 7 do show significant differences. Images are normalized to the dynamic range of the brighter of the three images, so that they can be visually compared. Note how the $\mathrm{OH}^{*}$ chemiluminescence image is brighter and the intensity profile at the bottom plot shows larger values downstream for the Surrogate flame. Qualitatively, the Surrogate fuel produces a flame with more soot in comparison to n-dodecane and n-heptane due to the heavier components and, especially, aromatic content. The LOL results obtained are in agreement with the expected trends discussed in section 1: shorter LOL for n-dodecane, followed by Surroage fuel and finally higher LOL for n-heptane.

These particular cases presented in detail show only a small sample of the behaviors observed for the whole test matrix. The trends observed in the full test matrix, however, were very consistent as shown in the following section. 




Figure 6: Ensemble-average $\mathrm{OH}^{*}$ chemiluminescence images of the flames produced by the two nozzles at particular test conditions. The intensity profiles shown in the bottom plot depict the column-wise intensity maximum of each image. In this case the fuel is $\mathrm{n}$-heptane, rail pressure is $150 \mathrm{MPa}$, ambient density is $22.8 \mathrm{~kg} / \mathrm{m}^{3}$, oxygen concentration is $15 \%$ and ambient temperature is $970 \mathrm{~K}$. 


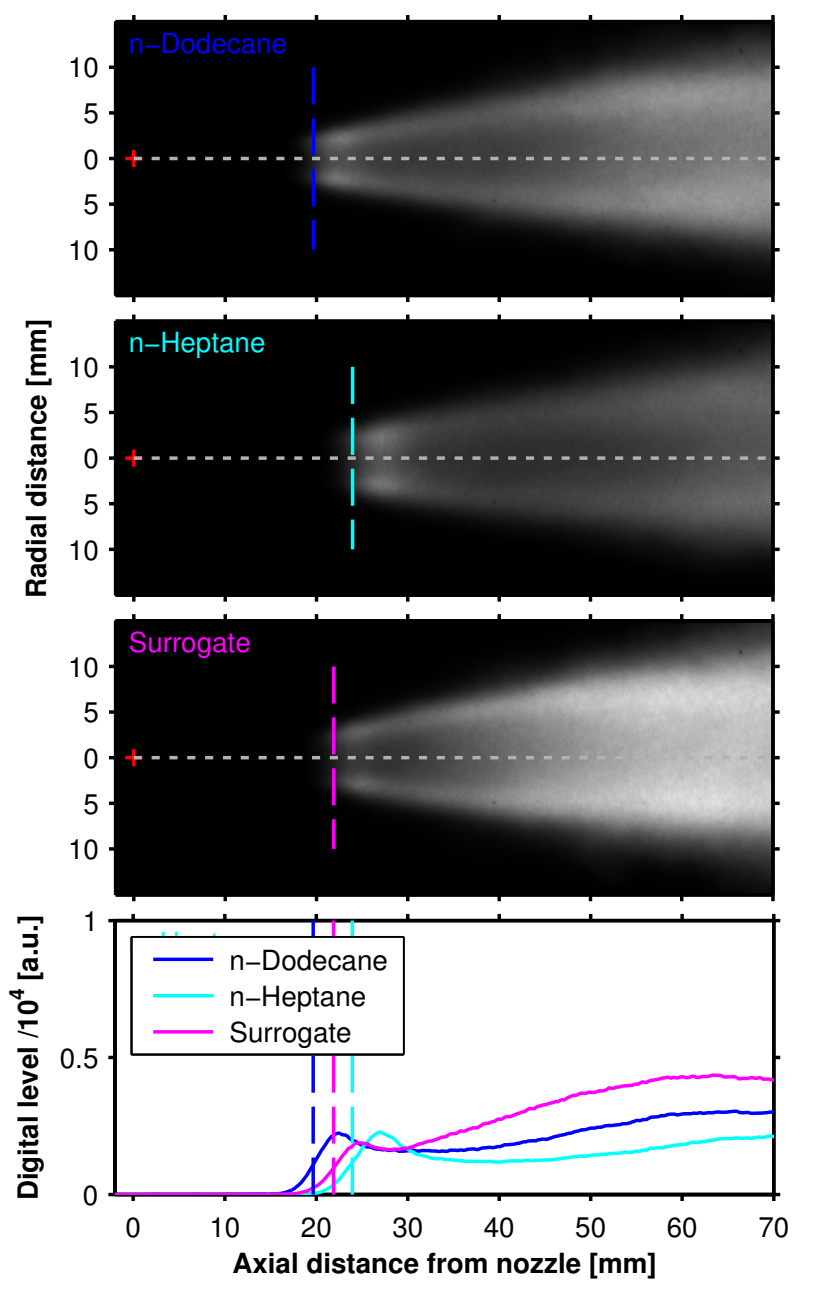

Figure 7: Ensemble-average $\mathrm{OH}^{*}$ chemiluminescence images of the flames produced by the three fuels at particular test conditions. The intensity profiles shown in the bottom plot depict the column-wise intensity maximum of each image. In this case the nozzle is $k 15$, rail pressure is $150 \mathrm{MPa}$, ambient density is $22.8 \mathrm{~kg} / \mathrm{m}^{3}$, oxygen concentration is $15 \%$ and ambient temperature is $900 \mathrm{~K}$. 


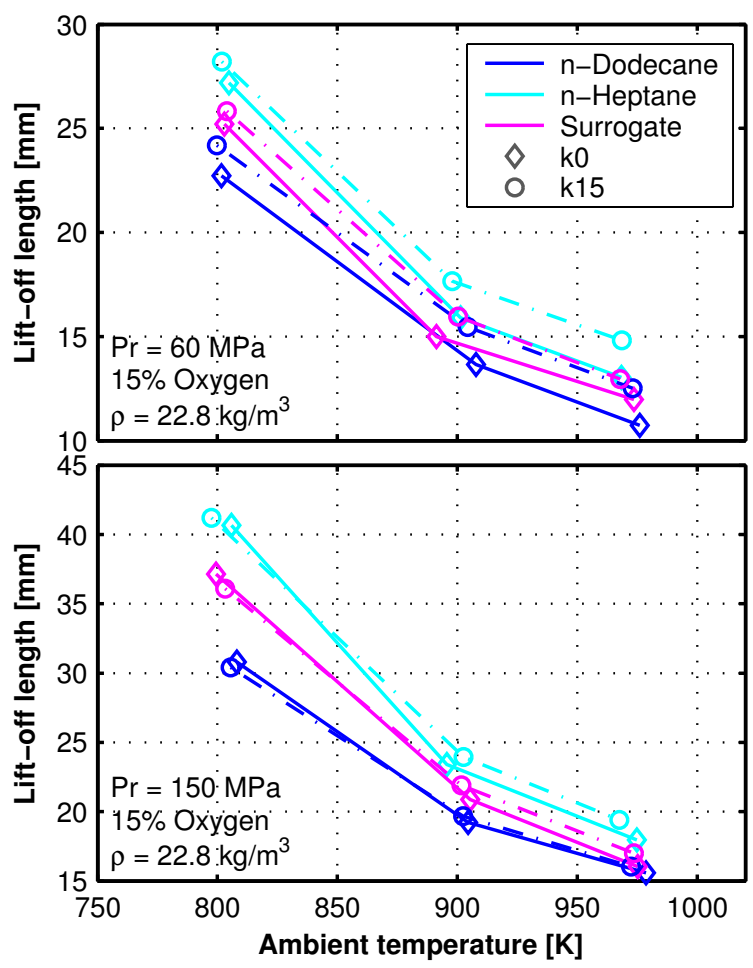

Figure 8: Lift-off length as a function of ambient temperature for all nozzles and fuels at an ambient density of $22.8 \mathrm{~kg} / \mathrm{m}^{3}$, an oxygen concentration of $15 \%$ and rail pressures of $60 \mathrm{MPa}$ (top) and $150 \mathrm{MPa}$ (bottom).

\subsubsection{Parametric variations}

This section presents LOL results for a larger window of test conditions and parametric variations. Figure 8 presents stabilized LOLs for all nozzles and fuels in a subset of the whole dataset, a sweep of ambient temperature at high and low rail pressures. First, it is easily noticeable how fuels are stratified in terms of LOL. n-Heptane consistently showed the longest LOLs, followed by the Surrogate fuel. Pickett et al. [38] and later Pastor et al. [51] observed that LOL was mainly controlled by ignition delay time, rather \& than flame velocity. Since there is very little reason to suspect significantly different flame velocities among these fuels $[52,53]$, the observations in these study concur with that conclusion: regarding fuel properties, LOL is mainly determined by the reactivity of the fuel.

12 On another line, note in Figure 8 how LOL increases considerably with 
rail pressure. This is also explained by the relationship between LOL and ignition delay: for larger injection pressures - thus, larger injection velocities [30] - fuel travels a longer distance for that given ignition delay time.

Figure 8 also shows the effect of nozzle geometry over LOL. Under virtually all conditions tested, the cylindrical $k 0$ produced shorter LOLs when compared to the conical nozzle $k 15$. All previous studies of these exact nozzles showed that differences in the development of the sprays produced by the two nozzles are reduced as rail pressure is increased [30-32]. Even though differences in hydraulic characteristics indeed increase with rail pressure [30], the higher injection and entrainment velocities induced by higher rail pressure suppress the small effects of nozzle geometry over the development of turbulent profiles in the spray and momentum exchange between the spray and the ambient gas [30-32]. This trend is also present in the LOL results, where the difference in LOL is reduced with increasing rail pressure. This proves consistency in the behavior of these nozzles in terms of isothermal liquid spray formation [30, 32], evaporative inert spray formation [31] and LOL stabilization of reactive sprays presented in this study.

Note that the hydraulic characterization of these nozzles, presented by Payri et al. [30], showed that the cylindrical nozzle $k 0$ features larger outlet flow velocities in comparison to the conical nozzle $k 15$, due to the area contraction. Higher velocity should also translate into larger LOL, but in this case the cylindrical nozzle geometry also produces larger spreading angles and fluctuations [30-32] which dominate over the higher velocity to produce shorter LOL after all.

Moreover, Figure 9 shows a subset of the the LOL results as a function of ambient temperature, for all fuels, in this case illustrating the effect of oxygen concentration. Note the large differences in LOL due to the oxygen concentrations. Even though laminar flame velocities are indeed strongly affected by equivalence ratio $[52,53]$, the different LOL values observed here for the two oxygen concentrations are attributed to the corresponding ignition delay times.

Figure 10 depicts a subset of the LOL results as a function of ambient density, for all nozzles and fuels. Note that the effect of ambient density is very straight forward: higher density implies that more oxygen is available to oxidize the fuel and thus, shorter ignition delays are expected, which reduce the corresponding LOL $[37,38]$. 


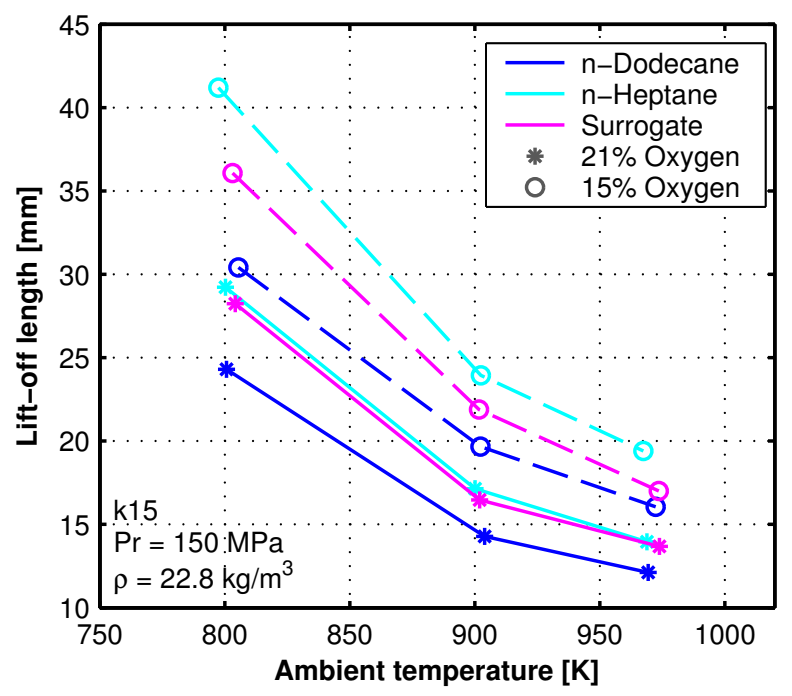

Figure 9: Lift-off length as a function of ambient temperature for all fuels and the two oxygen concentrations tested. In this case, the nozzle is $k 15$, ambient density is $22.8 \mathrm{~kg} / \mathrm{m}^{3}$ and rail pressure is $150 \mathrm{MPa}$.

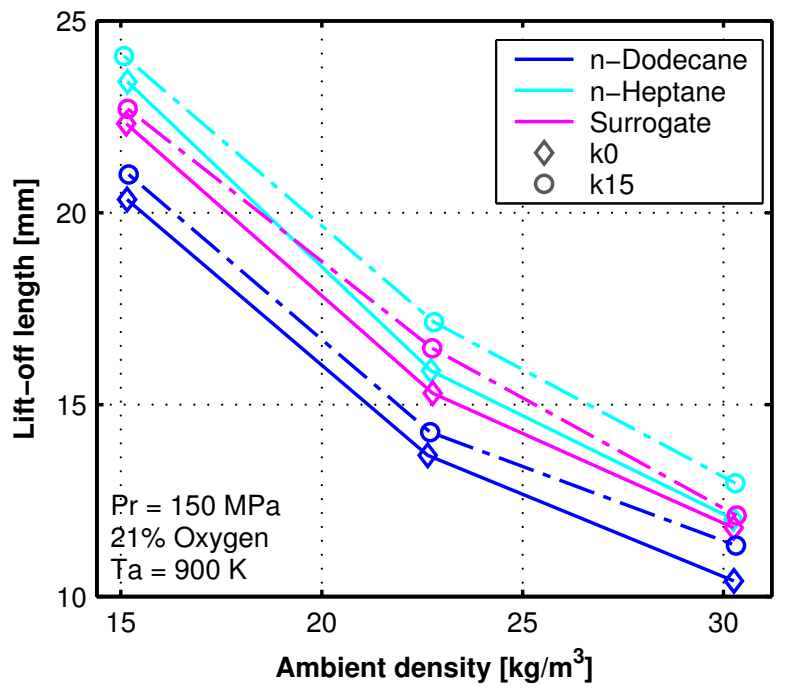

Figure 10: Lift-off length as a function of ambient density for all nozzles and fuels at a rail pressure of $150 \mathrm{MPa}$, an oxygen concentration of $21 \%$ and an ambient temperature of $900 \mathrm{~K}$. 


\subsection{Ignition delay}

Analogous to the LOL results section, it is also interesting to review the parameters affecting ID as known from the literature. These are fuel composition, ambient temperature, ambient density, ambient oxygen concentration, injection pressure and nozzle geometry $[33,36,37,51]$. Because of the large data base of the present investigation, select cases will be presented to illustrate the effect of each variable studied.

\subsubsection{Tracer signals}

Figures 11 and 12 present the time evolution of the tracers signals involved in the SSI detection. The top part of each figure shows the result of the pixel-wise intensity sum within the spray boundary (total intensity signal), while the bottom part of each figure shows its derivative (total intensity increment). As Figure 2 illustrates, at the first onset of chemical reactions, also known as start of cool flames (SoCF), the spray becomes transparent and the slope of the total intensity values changes suddenly. This transparent phase may not occur in some test conditions where ignition delays are very short, but the rest of the process develops in a very defined fashion. After this first stage, the spray tip appears again in the image and the total intensity values increase rapidly (in the inverted image, thus, darken in the actual image) to then steadily keep increasing with the spray growth. Benajes et al. [33], Payri et al. [36, 49] demonstrated that it is possible to correlate this rapid increase in total intensity values to the SSI. At the SSI, the total intensity signal slope reaches a maximum, as a result of the high temperature combustion, which causes rapid spray volume expansion but also changes refractive indexes inside the spray, darkening the spray or in fact making it brighter in the inverted image.

Benajes et al. [33], Payri et al. [36] studied in detail the effects of ambient temperature, oxygen concentration, density and injection pressure over these tracer signals, and the results found in this study follow closely the trends reported in those studies [33, 36]. Therefore, this section will focus only on the effects of nozzle geometry and fuel.

Figure 11 depicts a comparison of these tracer signals, both total intensity (top) and total intensity increment (bottom), produced by the two nozzles at particular test conditions. Payri et al. [30, 31, 32] demonstrated that sprays produced by the cylindrical nozzle $k 0$ features larger spreading angles in comparison to those produced by the conical nozzle $k 15$. This is translated into larger line-of-sight area which, at the same time, increases the total 
intensity value and its increments in time. Figure 11-bottom shows two maximums which correspond to the two SSI timings of the sprays produced by the two nozzles. Note that the spray produced by the conical nozzle $k 15$ ignites before the spray produced by nozzle $k 0$, while the latter shows a higher maximum which can be associated with a more pre-mixed combustion $[33,36]$. Even though this is a single example at particular test conditions, this trend was found to be consistent throughout the complete test matrix, as will be discussed later in the paper.

Fuels, on the other hand, do not alter the vapor spray spreading angle and penetration significantly [31], so the line-of-sight spray area is similar between fuels, which implies similar total intensity signals before ignition, as depicted by Figure 12. In these and virtually all conditions tested, ndodecane sprays ignite the earliest, followed by Surrogate sprays and last, n-heptane sprays, as will be discussed next. As explained also for Figure 11, longer ignition delays imply a more pre-mixed combustion which produces a sharper slope of the total intensity signal and thus, a larger maximum in the total intensity increment signal. After ignition is complete and diffusion takes over, the three signals behave similarly, as shown in both the top and bottom parts of Figure 12.

\subsubsection{Parametric variations}

A larger set of data is presented in Figure 13, with the top and bottom parts showing sub-sets of injections at $60 \mathrm{MPa}$ and $150 \mathrm{MPa}$ respectively. As expected from the literature, increasing ambient temperature increases the reactivity of the ambient gas which decreases IDs [24, 26, 33, 36, 38, 49-51]. Also, as Payri et al. [10, 36] observed, IDs decrease with increasing rail pressure, which is the result of faster liquid break-up and mixture preparation.

Moreover, Figure 13 shows that, in all cases, n-dodecane sprays feature the shortest SSI delays, followed by Surrogate sprays and last, n-heptane. Also as stated before, the conical nozzle $k 15$ produces sprays with slightly shorter SSI delays when compared to the cylindrical nozzle $k 0$, this will be discussed further at the end of this section.

Figures 14 and 15 illustrate the effect of ambient oxygen concentration and ambient density over the SSI delay. Results are in good agreement with the trends found in the literature, increasing oxygen concentration and ambient density decreases IDs [33, 36, 38]. At these relatively low ambient temperatures, chain-branching reactions are highly dependent on fuel reactivity and oxygen availability for the formation of radicals [51]. These figures 

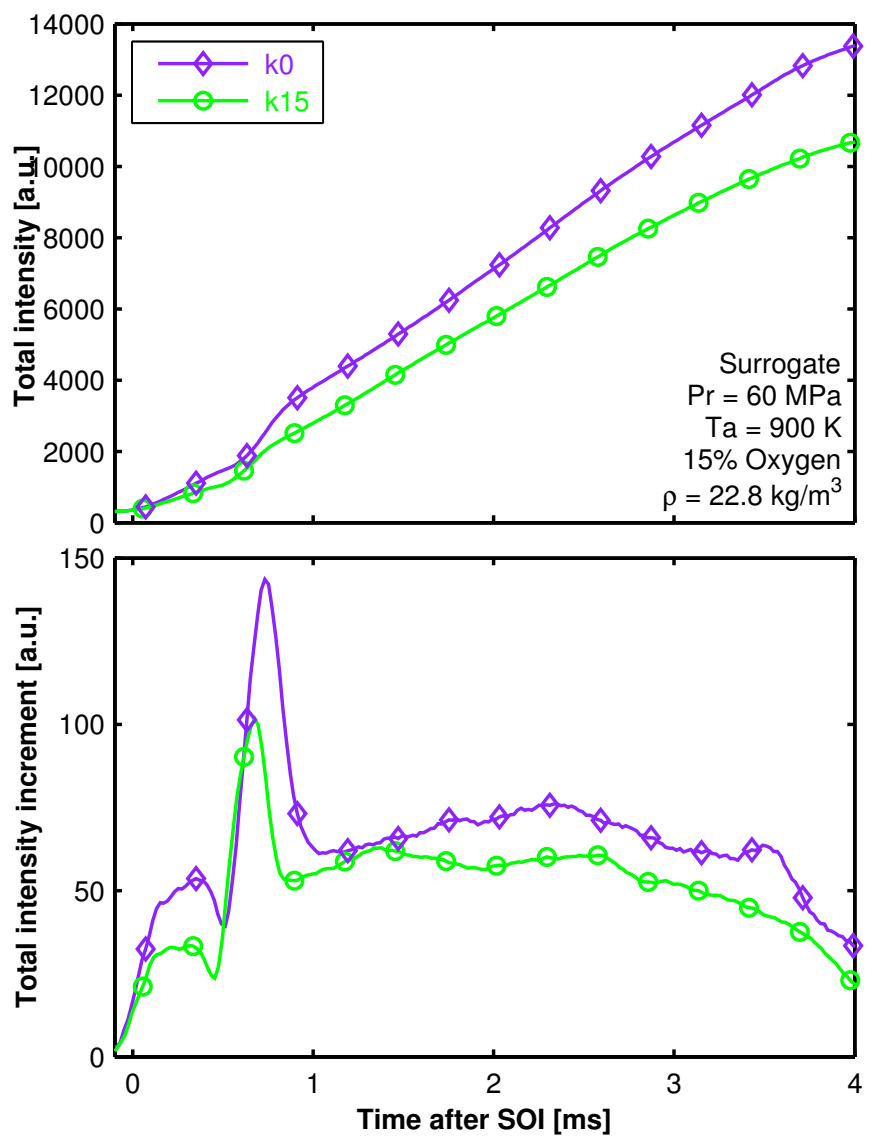

Figure 11: Total spray intensity (top) and intensity increment (bottom) tracer signals for the two nozzles at particular test condition. In this case the fuel is the Surrogate, rail pressure is $60 \mathrm{MPa}$, ambient density is $22.8 \mathrm{~kg} / \mathrm{m}^{3}$, ambient temperature is $900 \mathrm{~K}$ and oxygen concentration is $15 \%$. 

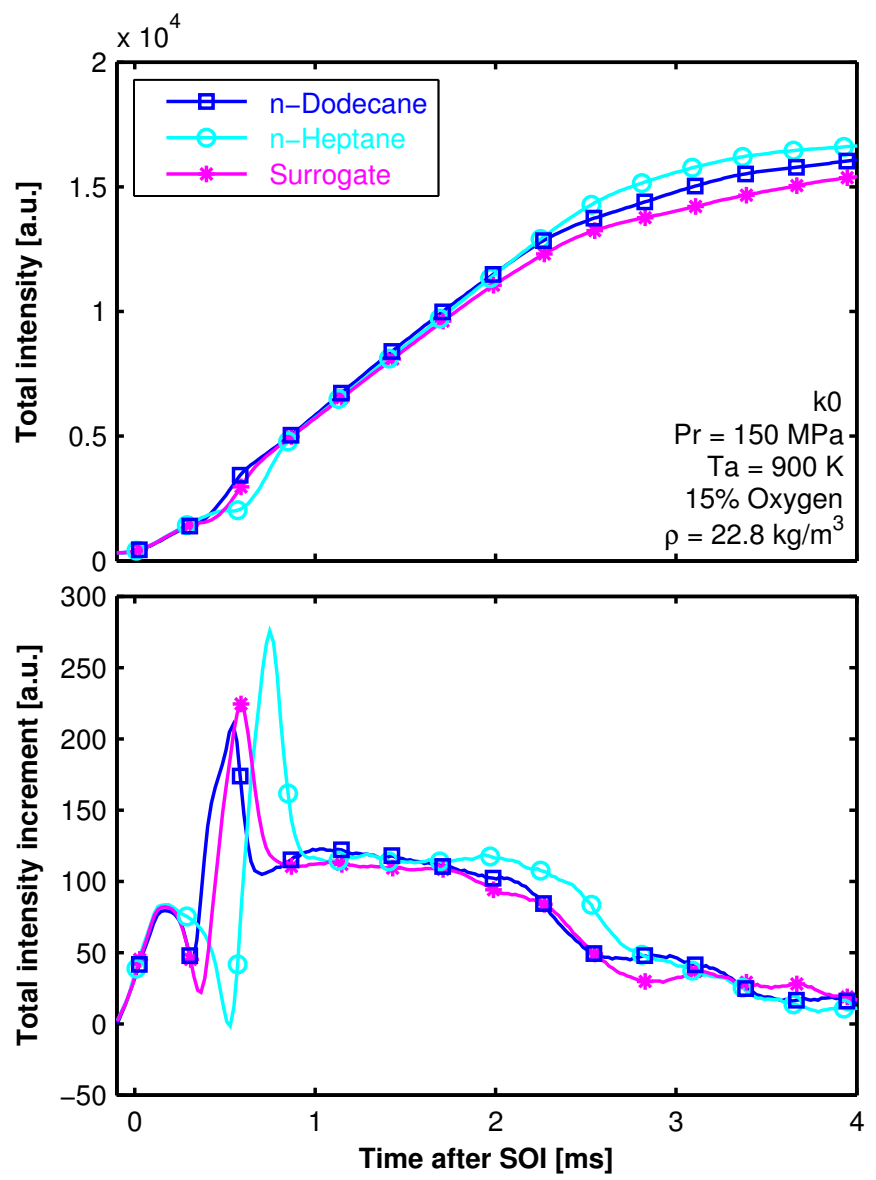

Figure 12: Total spray intensity (top) and intensity increment (bottom) tracer signals for the three fuels at particular test conditions. In this case the nozzle is $k 0$, rail pressure is $150 \mathrm{MPa}$, ambient density is $22.8 \mathrm{~kg} / \mathrm{m}^{3}$, ambient temperature is $900 \mathrm{~K}$ and oxygen concentration is $15 \%$. 

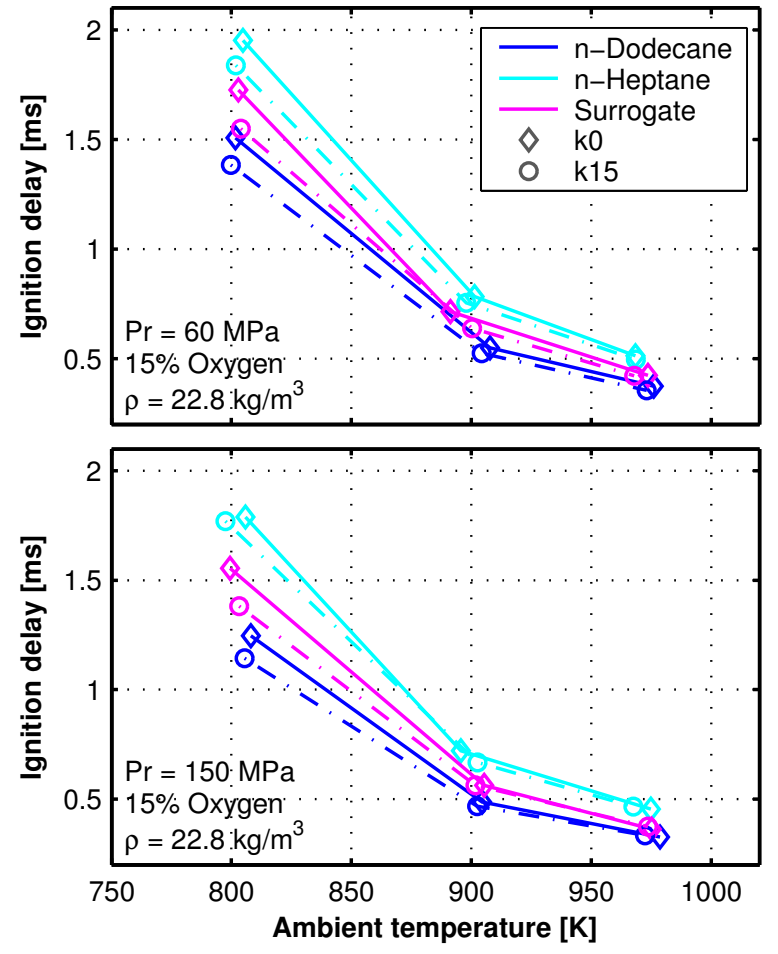

Figure 13: Ignition delay after SOI as a function of ambient temperature for all nozzles and fuels at an ambient density of $22.8 \mathrm{~kg} / \mathrm{m}^{3}$, an oxygen concentration of $15 \%$ and rail pressures of $60 \mathrm{MPa}$ (top) and $150 \mathrm{MPa}$ (bottom). 


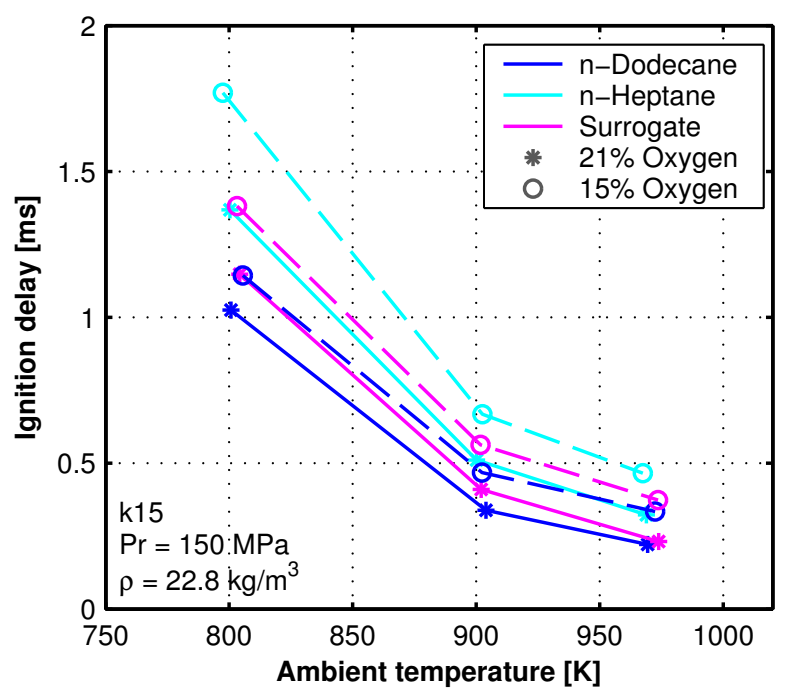

Figure 14: Ignition delay after SOI as a function of ambient temperature for all fuels and the two oxygen concentrations tested. In this case, the nozzle is $k 15$, ambient density is $22.8 \mathrm{~kg} / \mathrm{m}^{3}$ and rail pressure is $150 \mathrm{MPa}$.

also show that the different fuels respond consistently, in terms of ignition performance, to variations in ambient conditions, as is also the case for the nozzle geometry.

\subsubsection{Further discussion on the effect of nozzle geometry over the SSI}

The effect of nozzle geometry over the ignition performance of the fuel sprays was found to be very consistent throughout the full test matrix, as Figures 13, 14 and 15 illustrate. The conical nozzle $k 15$ produces sprays that, in average, feature $5.1 \%$ shorter SSI delays in comparison to those produced by the cylindrical nozzle $k 0$. It is important to point out that similar results were previously reported by Kong and Bae [2] and Payri et al. [10] from their studies in optically accessible engines, both of which found that conical nozzles produced shorter ignition delays in comparison to cylindrical nozzles, but these results contradict the numerical predictions reported by Som et al. [15]. This contrast, along the little information found in the literature on the extent of the effect of nozzle geometry over ignition performance of diesel sprays, leave room for further discussions on the subject, and additional analyses - both numerical but also experimental - should be performed to arrive at solid conclusions. 


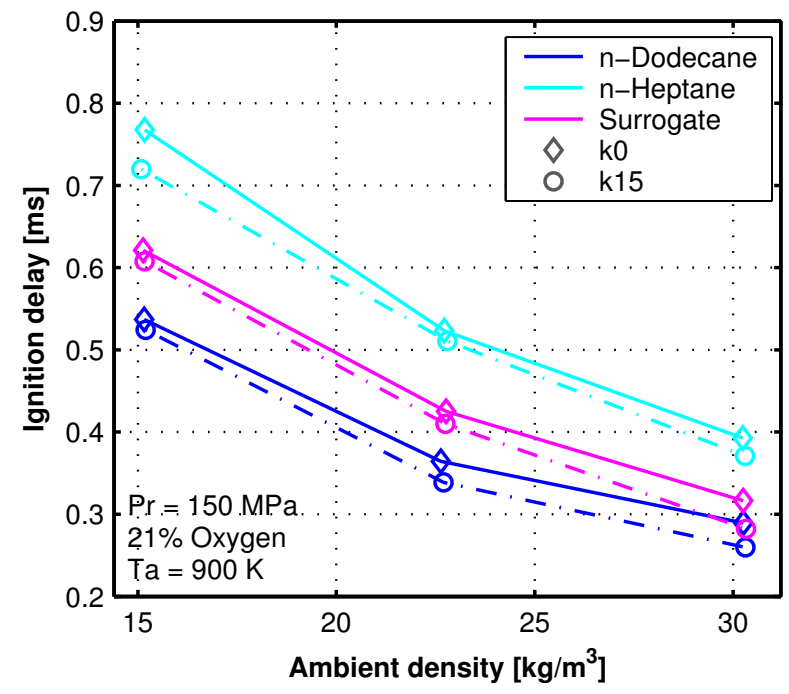

Figure 15: Ignition delay as a function of ambient density for all nozzles and fuels at a rail pressure of $150 \mathrm{MPa}$, an oxygen concentration of $21 \%$ and an ambient temperature of $900 \mathrm{~K}$.

In the case of this study, as the test matrix is so large and the trend between nozzles is so consistent, hypotheses should be discussed. The behavior observed might be unexpected at first, since the cylindrical nozzle $k 0$ features stronger turbulent velocity profiles at the outlet orifice that produce larger spreading angles and spray boundary fluctuations [30-32], which consequently lead to shorter liquid lengths [31]. Shorter liquid lengths can mislead one to expect shorter SSI delays because of the often associated faster liquid breakup and mixture preparation. Nevertheless, in these mixing-limited sprays, liquid length is strongly dependent on spreading angle, which the authors believe is the dominant parameter for the shorter liquid lengths featured by the cylindrical nozzle $k 0$. In their studies, Kong and Bae [2] and Payri et al. [10] attribute the shorter ignition delays found for their conical nozzles - in comparison to their cylindrical nozzles - to better atomization and liquid breakup, due to the thinner liquid core produced by the smaller nozzle diameter of the conical nozzles. This could also be the case for the present study. On the same lines, even if the two nozzles in this study were assumed to produce sprays with similar break-up/vaporization times or even shorter for the cylindrical nozzle, at the moment either spray reached vaporized ignitable mixtures the local equivalence ratio at the ignition location 
of the spray produced by the cylindrical nozzle $k 0$ would be expected to be lower than that of the spray produced by nozzle $k 15$, because of its significantly larger spread volume [31, 54] at virtually similar injected mass [30]. As it is largely known, the reaction paths at low temperatures are dependent on radical species formed directly from the fuel, so richer mixtures oxidize faster $[21,55]$.

Figure 16 presents a sequence of Schlieren images showing particular ignition events for the sprays produced by the two nozzles at equivalent test conditions. Each row is labeled with the corresponding elapsed time after SOI, and the detected contours are shown to illustrate the spray line-of-sight area. The spray produced by the cylindrical nozzle $k 0$ (left side of Figure 16) ignites later than the spray produced by the conical nozzle $k 15$ (right side of Figure 16), the difference in this case is small at $21 \mu \mathrm{s}$ but still appreciable in the images. It can be seen in this figure that, at the corresponding times of SSI for each nozzle (indicated at the top of each column), the spray produced by the cylindrical nozzle $k 0$ has spread considerably more, as was expected from the behavior of their inert vapor sprays [31]. The complete SSI delay time is a composition of the liquid break-up, fuel vaporization and chemical kinetic mechanisms. When comparing nozzles in this study, SSI delay results lead to think that the chemical kinetics are the dominant factor to the final outcome of the SSI delay behavior, due to the differences in local equivalence ratios between the sprays produced by the two nozzles. In cases with larger differences in ignition delay between nozzles, the spray produced by the cylindrical nozzle will have penetrated and spread further into the ambient gas, probably igniting at even lower equivalence ratios. This is also observable in both the top and bottom parts of Figure 11, since the total intensity signal is also a measurement of the line-of-sight spray area detected, and lines that corresponds to the cylindrical nozzle $k 0$ stays above lines that corresponds to the conical nozzle $k 15$. This trend between nozzles regarding total intensity signals was consistent along the full test matrix. Moreover, Figure 6 also shows larger intensity profiles downstream of the LOL for the conical nozzle $k 15$ that could, qualitatively, be associated to a more sooting flame, also indicating richer equivalence ratios near the LOL region.

Finally, even though soot formation is out of the scope of this publication, the authors point out that a further study should be carried out to analyze soot formation for the three fuels. In particular, the Surrogate fuel is of interest, since it is conceptualized to better mimic the soot-related behavior of real diesel fuel, as its $\mathrm{PAH}$ content should increase soot formation in comparison 


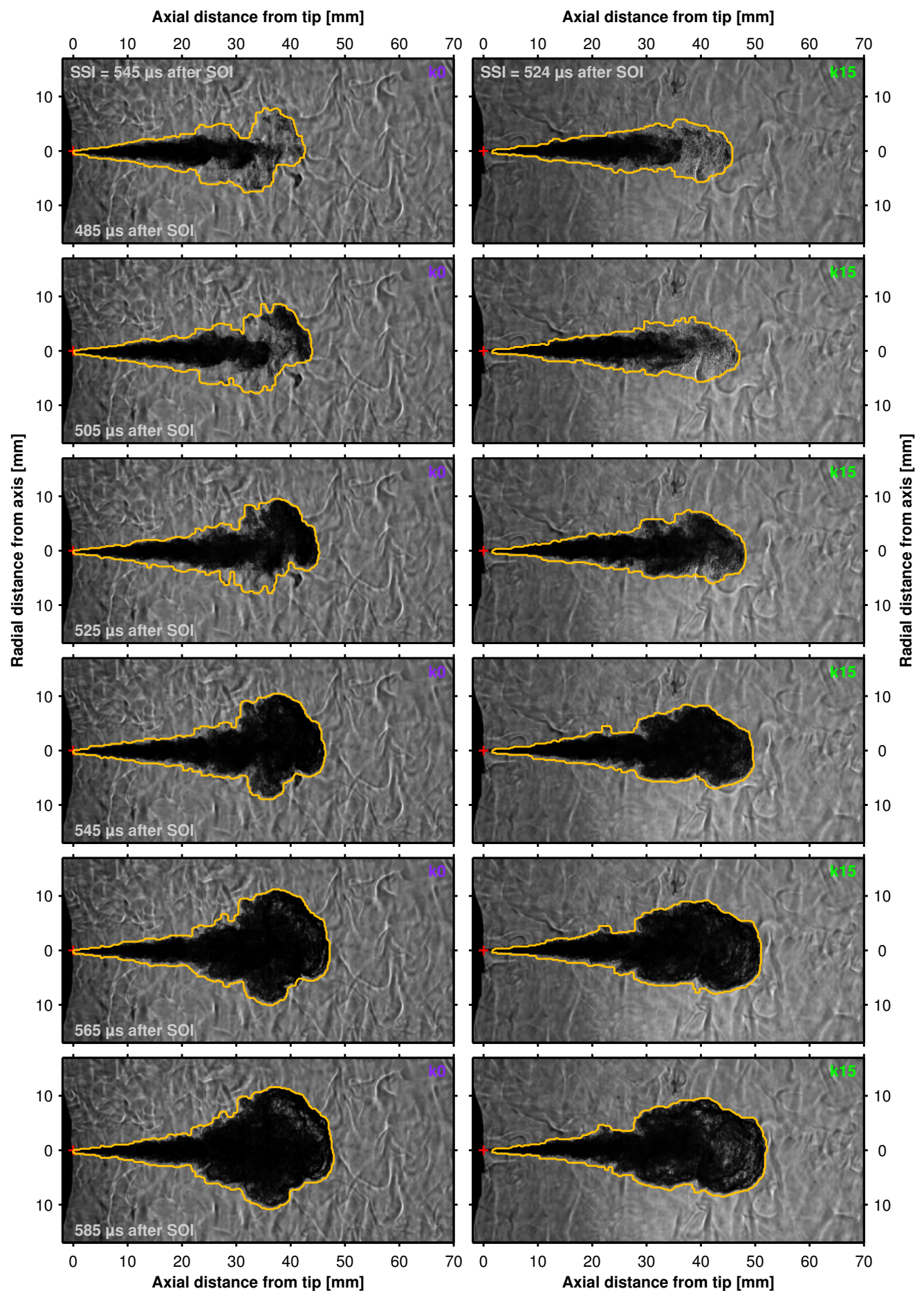

Figure 16: Time sequence of Schlieren images of two injection events of the sprays produced by $k 0$ and $k 15$ nozzles. Images have been trimmed both in the radial and axial directions from their original size, for better fit in this figure. The contours detected are plotted to scale over the original Schlieren images. In this case, fuel is n-dodecane, rail pressure is $150 \mathrm{MPa}$, ambient density is $15.2 \mathrm{~kg} / \mathrm{m}^{3}$, ambient temperature is $900 \mathrm{~K}$ and the oxygen concentration is $21 \%$. 
to pure $n$-alkanes. However, it is also possible that the SSI delay induced by the $\alpha$-methylnaphthalene content is large enough so to delay ignition to a point where the local equivalence ratio is very low, which would render a less-sooting flame: a similar situation what was found for the secondary fuel of the ECN, which is a mixture of n-dodecane and m-xylene [36, 56].

\section{Conclusions}

This study is a continuation of previous work by the authors. In previous publications, the authors studied the internal flow characteristics, isothermal liquid spray development, and evaporative inert spray development for the same nozzle geometries and fuels. Current study reports the ignition delay through Schlieren technique, and flame lift-off length through $\mathrm{OH}^{*}$ chemiluminescence visualization, aiming to enhance the size and quality of the database already published. The nozzle geometries consist of a conical nozzle and a cylindrical nozzle with $8.6 \%$ larger outlet diameter when compared to the conical nozzle. Among the three fuels, two are pure componentsn-heptane and n-dodecane - while the third consists of a three-component surrogate to better represent the physical and chemical properties of diesel fuel.

Reacting spray is found to penetrate faster than non-reacting spray due to combustion induced acceleration after ignition. Higher oxygen concentration, and ambient temperature enhance the reactivity leading to higher spray tip penetration. Injection pressure does not affect the reactivity significantly and hence, influences spray penetration through momentum-similar to a non-reacting spray.

Both ignition delay and lift-off length are found to be shortest and longest for n-dodecane and n-heptane, respectively, while the surrogate fuel falls in-between the two pure component fuels. Both ignition delay and lift-off length are found to decrease with increase in oxygen concentration, ambient temperature, and density, in agreement with previous works found in the literature. The conical nozzle, in spite of longer lift-off length is found to have shorter ignition delay, when compared to the cylindrical nozzle. This could be due to smaller liquid vain that breaks-up and vaporizes quicker to form a reactive mixture faster than the droplets from cylindrical nozzle, but could also be to the fact that the spray produced by the cylindrical nozzle spreads considerably more, which reduces the local equivalence ratio at the time of ignition. This trend between nozzles was found to be in agreement 
to previous experimental studies $[2,10]$ but in contradiction to numerical predictions [15]. Hence, further analysis for a more in-depth understanding of this mechanics involved in this process should be considered.

The experimental findings from this work on the macroscopic spray behavior, and the large database obtained (available for download at: http: //www. cmt.upv.es/DD01.aspx), could be used to validate CFD models that could help the community understand the fundamental driving mechanisms behind these observations.

\section{Acknowledgments}

This work was sponsored by Ministerio de Economía y Competitividad of the Spanish Government in the frame of the Project "Estudio de la interacción chorro-pared en condiciones realistas de motor", Reference TRA201567679-c2-1-R. Additionally, the employed nozzles and Diesel surrogate were provided and defined by GM R\&D.

The authors would like to thank José Enrique Del Rey and María del Carmen Tomás for their collaboration in the setup of the experiments and laboratory work, and Guillermo Miró for his help measuring fuel properties.

\section{References}

[1] E. Mancaruso, B. M. Vaglieco, Spectroscopic analysis of the phases of premixed combustion in a compression ignition engine fuelled with diesel and ethanol, Applied Energy 143 (2015) 164-175, ISSN 03062619, doi: $\backslash$ bibinfo $\{$ doi $\}\{10.1016 /$ j.apenergy.2015.01.031\}.

[2] J. Kong, C. Bae, Effect of a conical nozzle orifice on the combustion and emissions in a direct- injection compression ignition engine under lowload conditions, Proceedings of the Institution of Mechanical Engineers, Part D: Journal of Automobile Engineering 229 (1) (2015) 3-13, ISSN 0954-4070, doi: bibinfo\{doi\}\{10.1177/0954407013491894\}, URL http: //pid.sagepub.com/lookup/doi/10.1177/0954407013491894.

[3] Z. Wu, T. Bao, Q. Zhang, S. Yan, J. Deng, Experimental study on spray combustion characteristics of gasolinediesel blended fuel in a controllable active thermo-atmosphere, Fuel 135 (2014) 374-379, ISSN 00162361, doi: \bibinfo\{doi\}\{10.1016/j.fuel.2014.06.073\}, URL http:// linkinghub.elsevier.com/retrieve/pii/S0016236114006395. 
[4] T. Sarjovaara, M. Larmi, Dual fuel diesel combustion with an E85 ethanol/gasoline blend, Fuel 139 (2015) 704-714, ISSN 00162361, doi: $\backslash$ bibinfo\{doi\}\{10.1016/j.fuel.2014.09.049\}, URL http://linkinghub. elsevier.com/retrieve/pii/S0016236114009181.

[5] F. J. Salvador, J. Martínez-López, J. V. Romero, M. D. Roselló, Influence of biofuels on the internal flow in diesel injector nozzles, Mathematical and Computer Modelling 54 (7-8) (2011) 1699-1705, ISSN 08957177, doi: bibinfo\{doi\}\{10.1016/j.mcm.2010.12.010\}.

[6] T. D. Fansler, S. E. Parrish, Spray measurement technology: a review, Measurement Science and Technology 26 (1) (2015) 012002, ISSN 0957-0233, doi:〈bibinfo\{doi\}\{10.1088/0957-0233/ 26/1/012002\}, URL http://stacks.iop.org/0957-0233/26/i=1/a= 012002?key=crossref . a51a57d78742e5d88aea3d6f06688efc.

[7] R. Payri, S. Molina, F. J. Salvador, J. Gimeno, A study of the relation between nozzle geometry, internal flow and sprays characteristics in diesel fuel injection systems, KSME International Journal 18 (7) (2004) 1222-1235, ISSN 1226-4865, doi: \bibinfo $\{$ doi $\}\{10.1007 / \mathrm{BF} 02983297\}$, URL http://link. springer.com/article/10.1007/BF02983297.

[8] S. Huang, P. Deng, R. Huang, Z. Wang, Y. Ma, H. Dai, Visualization research on spray atomization, evaporation and combustion processes of ethanol-diesel blend under LTC conditions, Energy Conversion and Management 106 (2015) 911-920, ISSN 01968904, doi: bibinfo\{doi $\}\{10$. 1016/j.enconman.2015.10.028\}, URL http://dx.doi.org/10.1016/j . enconman.2015.10.028.

[9] C. Yao, P. Geng, Z. Yin, J. Hu, D. Chen, Y. Ju, Impacts of nozzle geometry on spray combustion of high pressure common rail injectors in a constant volume combustion chamber, Fuel 179 (2016) 235-245, ISSN 00162361, doi: \bibinfo\{doi\}\{10.1016/j.fuel.2016.03.097\}, URL http:// linkinghub.elsevier.com/retrieve/pii/S0016236116301399.

[10] R. Payri, F. J. Salvador, J. Gimeno, J. De la Morena, Effects of nozzle geometry on direct injection diesel engine combustion process, Applied Thermal Engineering 29 (10) (2009) 2051-2060, ISSN 13594311, doi: $\backslash$ bibinfo $\{$ doi $\}\{10.1016 / \mathrm{j}$.applthermaleng.2008.10.009\}. 
[11] L. C. Ganippa, S. Andersson, J. Chomiak, A. Matsson, Combustion characteristics of diesel sprays from equivalent nozzles with sharp and rounded inlet geometries, Combustion Science and Technology 175 (6) (2003) 1015-1032, ISSN 0010-2202, doi:〈bibinfo $\{$ doi $\}\{10.1080 /$ $00102200302350\}$.

[12] S. H. Park, H. K. Suh, C. S. Lee, Effect of Cavitating Flow on the Flow and Fuel Atomization Characteristics of Biodiesel and Diesel Fuels, Energy \& Fuels 22 (1) (2008) 605-613, ISSN 0887-0624, doi: bibinfo\{doi\}\{10.1021/ef7003305\}, URL http://pubs.acs.org/doi/ abs/10.1021/ef7003305.

[13] S. Som, S. K. Aggarwal, Effects of primary breakup modeling on spray and combustion characteristics of compression ignition engines, Combustion and Flame 157 (6) (2010) 1179-1193, ISSN 00102180, doi: bibinfo\{doi\}\{10.1016/j.combustflame.2010.02.018\}, URL http://dx. doi.org/10.1016/j. combustflame.2010.02.018.

[14] R. Payri, F. J. Salvador, J. Gimeno, L. D. Zapata, Diesel nozzle geometry influence on spray liquid-phase fuel penetration in evaporative conditions, Fuel 87 (7) (2008) 1165-1176, ISSN 00162361, doi:\bibinfo\{doi\} \{10.1016/j.fuel.2007.05.058\}, URL http://www.sciencedirect.com/ science/article/pii/S0016236107003080.

[15] S. Som, A. I. Ramírez, D. E. Longman, S. K. Aggarwal, Effect of nozzle orifice geometry on spray, combustion, and emission characteristics under diesel engine conditions, Fuel 90 (3) (2011) 1267-1276, ISSN 00162361, doi: \bibinfo\{doi\}\{10.1016/j.fuel.2010.10.048\}, URL http:// dx.doi.org/10.1016/j.fuel.2010.10.048.

[16] M. Battistoni, C. Grimaldi, F. Mariani, Coupled Simulation of Nozzle Flow and Spray Formation Using Diesel and Biodiesel for CI Engine Applications, SAE Technical Paper 2012-01-1267 doi: bibinfo\{doi $\}\{10$. 4271/2012-01-1267\}, URL http://www.sae.org/technical/papers/ 2012-01-1267.

[17] F. J. Salvador, J. Gimeno, J. M. Pastor, P. Martí-Aldaraví, Effect of turbulence model and inlet boundary condition on the diesel spray behavior simulated by an eulerian spray atomization (ESA) model, International Journal of Multiphase Flow 65 (2014) 108-116, ISSN 03019322, 
doi: bibinfo\{doi\}\{10.1016/j.ijmultiphaseflow.2014.06.003\}, URL http:

//dx.doi.org/10.1016/j.ijmultiphaseflow.2014.06.003.

[18] Q. Xue, M. Battistoni, C. F. Powell, D. E. Longman, S. Quan, E. Pomraning, P. K. Senecal, D. P. Schmidt, S. Som, An Eulerian CFD model and X-ray radiography for coupled nozzle flow and spray in internal combustion engines, International Journal of Multiphase Flow 70 (2015) 77-88, ISSN 03019322, doi:〈bibinfo\{doi\}\{10.1016/ j.ijmultiphaseflow.2014.11.012\}, URL http://linkinghub.elsevier. com/retrieve/pii/S0301932214002328.

[19] J. M. Desantes, J. M. Garcia-Oliver, J. M. Pastor, A. Pandal, E. Baldwin, D. P. Schmidt, Coupled/decoupled spray simulation comparison of the ECN spray a condition with the $\Sigma$-Y Eulerian atomization model, International Journal of Multiphase Flow 80 (2016) 89-99, ISSN 03019322, doi:〈bibinfo\{doi\}\{10.1016/j.ijmultiphaseflow.2015.12.002\}.

[20] M. Bardi, R. Payri, L.-M. Malbec, G. Bruneaux, L. M. Pickett, J. Manin, T. Bazyn, C. L. Genzale, Engine Combustion Network: Comparison of Spray Development, Vaporization, and Combustion in Different Combustion Vessels, Atomization and Sprays 22 (10) (2012) 807-842, ISSN 1044-5110, doi:`bibinfo\{doi\}\{10.1615/AtomizSpr.2013005837\}, URL http://www.dl. begellhouse. com/journals/6a7c7e10642258cc, 5b18f0e860ebc687, 20adc8ff175d5f43.html.

[21] H. Curran, P. Gaffuri, W. J. Pitz, C. Westbrook, A Comprehensive Modeling Study of n-Heptane Oxidation, Combustion and Flame 114 (1-2) (1998) 149-177, ISSN 00102180, doi: bibinfo\{doi $\}\{10$. 1016/S0010-2180(97)00282-4\}, URL http://linkinghub.elsevier. com/retrieve/pii/S0010218097002824.

[22] J. T. Farrell, N. P. Cernansky, F. L. Dryer, C. K. Law, D. G. Friend, C. A. Hergart, R. M. McDavid, A. K. Patel, C. J. Mueller, H. Pitsch, Development of an Experimental Database and Kinetic Models for Surrogate Diesel Fuels, SAE Technical Paper 2007-01-0201 doi: \bibinfo\{doi\}\{10.4271/2007-01-0201\}, URL http://papers.sae.org/ 2007-01-0201/.

[23] F. Battin-Leclerc, Detailed chemical kinetic models for the lowtemperature combustion of hydrocarbons with application to gasoline 
and diesel fuel surrogates, Progress in Energy and Combustion Science 34 (2008) 440-498, ISSN 03601285, doi:〈bibinfo $\{$ doi $\}\{10.1016 /$ j.pecs. 2007.10.002\}.

[24] M. Raju, M. Wang, P. K. Senecal, S. Som, D. E. Longman, A reduced diesel surrogate mechanism for compression ignition engine applications, in: Proceedings of the ASME 2012 Internal Combustion Engine Division Fall Technical Conference ICEF2012, American Society of Mechanical Engineers, Vancouver, doi: bibinfo\{doi\}\{ICEF2012-92045\}, 2012.

[25] R. H. Natelson, M. S. Kurman, N. P. Cernansky, D. L. Miller, Experimental investigation of surrogates for jet and diesel fuels, Fuel 87 (2008) 2339-2342, doi: \bibinfo\{doi\}\{10.1016/j.fuel.2007.11.009\}.

[26] W. J. Pitz, C. J. Mueller, Recent progress in the development of diesel surrogate fuels, Progress in Energy and Combustion Science 37 (3) (2011) 330-350, ISSN 0360-1285, doi: bibinfo\{doi\}\{10.1016/j.pecs.2010. 06.004\}, URL http://dx.doi.org/10.1016/j.pecs.2010.06.004.

[27] J. Luo, M. Yao, H. Liu, B. Yang, Experimental and numerical study on suitable diesel fuel surrogates in low temperature combustion conditions, Fuel 97 (2012) 621-629, ISSN 0016-2361, doi: bibinfo\{doi $\}\{10$. 1016/j.fuel.2012.02.057\}, URL http://dx.doi.org/10.1016/j.fuel. 2012.02.057.

[28] C. A. Idicheria, L. M. Pickett, Soot formation in Diesel combustion under high-EGR conditions, SAE Technical Paper 2005-01-3834 doi: $\backslash$ bibinfo\{doi $\}\{10.4271 / 2005-01-3834\}$.

[29] R. Payri, J. M. García-Oliver, M. Bardi, J. Manin, Fuel temperature influence on diesel sprays in inert and reacting conditions, Applied Thermal Engineering 35 (March) (2012) 185195, ISSN 13594311, doi: \bibinfo\{doi\}\{10.1016/j.applthermaleng.2011. 10.027\}, URL doi:10.1016/j.applthermaleng.2011.10.027http:// linkinghub.elsevier.com/retrieve/pii/S1359431111005655.

[30] R. Payri, J. P. Viera, V. Gopalakrishnan, P. G. Szymkowicz, The effect of nozzle geometry over internal flow and spray formation for three different fuels, Fuel 183 (2016) 20-33, ISSN 00162361, doi: $\backslash$ bibinfo\{doi\}\{10.1016/j.fuel.2016.06.041\}, URL http://linkinghub. elsevier.com/retrieve/pii/S0016236116304938. 
[31] R. Payri, J. P. Viera, V. Gopalakrishnan, P. G. Szymkowicz, The effect of nozzle geometry over the evaporative spray formation for three different fuels, Fuel (2017) 645-660ISSN 00162361, doi:\bibinfo\{doi\}\{10.1016/ j.fuel.2016.06.041\}, URL http://dx.doi.org/10.1016/j.fuel.2016. 10.064 .

[32] R. Payri, F. J. Salvador, J. Gimeno, J. P. Viera, Experimental analysis on the influence of nozzle geometry over the dispersion of liquid n-dodecane sprays, Frontiers in Mechanical Engineering 1 (2015) 1-10, ISSN 2297-3079, doi: \bibinfo $\{$ doi $\}\{10.3389 /$ fmech.2015. 00013\}, URL http://journal.frontiersin.org/Article/10.3389/ fmech.2015.00013/abstract.

[33] J. Benajes, R. Payri, M. Bardi, P. Martí-aldaraví, Experimental characterization of diesel ignition and lift-off length using a singlehole ECN injector, Applied Thermal Engineering 58 (1-2) (2013) 554-563, ISSN 13594311, doi: bibinfo\{doi $\}\{10.1016 / j$.applthermaleng. 2013.04.044\}, URL http://www.sciencedirect.com/science/ article/pii/S1359431113003153http://dx.doi.org/10.1016/j. applthermaleng. 2013.04.044.

[34] L. M. Pickett, S. Kook, T. C. Williams, Visualization of Diesel Spray Penetration, Cool-Flame, Ignition, High- Temperature Combustion , and Soot Formation Using High-Speed Imaging, SAE Int. J. Engines 2 (1) (2009) 439-459, doi: bibinfo\{doi\} \{10.4271/2009-01-0658\}.

[35] P. M. Lillo, L. M. Pickett, H. Persson, O. Andersson, S. Kook, Diesel Spray Ignition Detection and Spatial/Temporal Correction, SAE Paper 2012-01-1239 (2012) 1-21doi:〈bibinfo\{doi\}\{10.4271/2012-01-1239\}.

[36] R. Payri, J. P. Viera, Y. Pei, S. Som, Experimental and numerical study of lift-off length and ignition delay of a two-component diesel surrogate, Fuel 158 (2015) 957-967, ISSN 00162361, doi: $\backslash$ bibinfo\{doi\}\{10.1016/j.fuel.2014.11.072\}, URL http://linkinghub. elsevier.com/retrieve/pii/S0016236114011764.

[37] B. Higgins, D. L. Siebers, Measurement of the Flame Lift-Off Location on DI Diesel Sprays Using OH Chemiluminescence, SAE Paper 200101-0918 . 
[38] L. M. Pickett, D. L. Siebers, C. A. Idicheria, Relationship Between Ignition Processes and the Lift-Off Length of Diesel Fuel Jets, SAE Paper 2005-01-3843 (724).

[39] M. Meijer, L. Somers, J. Johnson, J. D. Naber, S.-Y. Lee, L.M. Malbec, G. Bruneaux, L. M. Pickett, M. Bardi, R. Payri, T. Bazyn, Engine Combustion Network (ECN): Characterization and comparison of boundary conditions for different combustion vessels, Atomization and Sprays 22 (9) (2012) 777-806, ISSN 1044-5110, doi:`bibinfo\{doi\}\{10.1615/AtomizSpr.2012006083\}, URL http://www .dl . begellhouse.com/journals/6a7c7e10642258cc, 64b3d5d415f8eb91, 0365a5274d55553b.html.

[40] R. Payri, J. Gimeno, J. P. Viera, A. H. Plazas, Needle lift profile influence on the vapor phase penetration for a prototype diesel direct acting piezoelectric injector, Fuel 113 (2013) 257265, ISSN 00162361, doi: \bibinfo\{doi\}\{10.1016/j.fuel.2013.05.057\}, URL http://www.sciencedirect.com/science/article/pii/ S0016236113004699http://dx.doi.org/10.1016/j.fuel.2013.05. 057.

[41] R. Payri, H. Climent, F. J. Salvador, a. G. Favennec, Diesel Injection System Modelling. Methodology and Application for a First-generation Common Rail System, Proceedings of the Institution of Mechanical Engineers, Part D: Journal of Automobile Engineering 218 (1) (2004) 8191, ISSN 0954-4070, doi: \bibinfo\{doi\}\{10.1243/095440704322829191\}.

[42] J. Benajes, R. Payri, S. Molina, V. Soare, Investigation of the influence of injection rate shaping on the spray characteristics in a diesel common rail system equipped with piston amplifier, ASME Journal of fluids engineering 127 (2005) 1102-1110.

[43] M. A. Reddemann, F. Mathieu, D. Martin, R. Kneer, The Influence of Fuel Properties on Spray Propagation, Atomization and Evaporation, in: ILASS 2010, September, 1-6, 2010.

[44] H. Pitsch, H. Barths, N. Peters, Three-dimensional Modeling of NOx and soot formation in DI-diesel engines using detailed chemistry based on the interactive flamelet approach, SAE Technical Paper 962057 doi: $\backslash$ bibinfo\{doi $\}\{10.4271 / 962057\}$. 
[45] J. M. Desantes, J. J. Lopez, J. M. Garcia-Oliver, J. M. Pastor, Evaporative Diesel spray modeling, Atomization and Sprays 17 (2007) 193 - 231, ISSN 1045-5110, doi: \bibinfo\{doi\}\{10.1615/AtomizSpr.v17.i3.10\}.

[46] E. W. Lemmon, M. O. McLinden, D. G. Friend, Thermophysical Properties of Fluid Systems, in: P. J. Linstrom, W. G. Mallard (Eds.), NIST Chemistry WebBook, NIST Standard Reference Database Number 69, URL http://webbook.nist.gov, 2011.

[47] Y. Jung, J. Manin, S. A. Skeen, L. M. Pickett, Measurement of Liquid and Vapor Penetration of Diesel Sprays with a Variation in Spreading Angle, SAE Technical Paper 2015-01-0946 doi:〈bibinfo\{doi $\}\{10.4271 /$ 2015-01-0946. Copyright\}.

[48] R. Payri, J. Gimeno, G. Bracho, D. Vaquerizo, Study of liquid and vapor phase behavior on Diesel sprays for heavy duty engine nozzles, Applied Thermal Engineering 107 (2016) 365-378, doi: bibinfo\{doi\}\{10.1016/j.applthermaleng.2016.06.159\}, URL http://dx.doi.org/10.1016/j. applthermaleng.2016.06.159http: //linkinghub.elsevier.com/retrieve/pii/S1359431116310730.

[49] R. Payri, F. J. Salvador, J. Manin, A. Viera, Diesel ignition delay and lift-off length through different methodologies using a multihole injector, Applied Energy 162 (2016) 541-550, ISSN 03062619, doi: bibinfo\{doi\}\{10.1016/j.apenergy.2015.10.118\}, URL http: //linkinghub.elsevier.com/retrieve/pii/S0306261915013549.

[50] B. Higgins, D. L. Siebers, A. Aradi, Diesel-Spray Ignition and PremixedBurn Behavior, SAE Technical Paper 2000-01-0940 (724).

[51] J. V. Pastor, J. M. Garcia-Oliver, J. J. Lopez, W. Vera-Tudela, An experimental study of the effects of fuel properties on reactive spray evolution using Primary Reference Fuels, Fuel 163 (X) (2016) 260-270, ISSN 00162361, doi: bibinfo\{doi\}\{10.1016/j.fuel.2015.09. 064\}, URL http://dx.doi.org/10.1016/j.fuel.2015.09.064http: //linkinghub.elsevier.com/retrieve/pii/S0016236115009618.

[52] M. Metghalchi, J. C. Keck, Burning velocities of mixtures of air with methanol, isooctane, and indolene at high pressure and temperature, Combustion and Flame 48 (1982) 191-210, ISSN 00102180, 
doi: bibinfo\{doi\}\{10.1016/0010-2180(82)90127-4\}, URL http: //linkinghub.elsevier.com/retrieve/pii/0010218082901274.

[53] S. Jerzembeck, N. Peters, P. Pepiotdesjardins, H. Pitsch, Laminar burning velocities at high pressure for primary reference fuels and gasoline: Experimental and numerical investigation, Combustion and Flame 156 (2) (2009) 292-301, ISSN 00102180, doi: $\backslash$ bibinfo $\{$ doi $\}\{10.1016 / j$. combustflame.2008.11.009\}, URL http://linkinghub.elsevier.com/ retrieve/pii/S0010218008003489.

[54] G. Lequien, S. Skeen, J. Manin, L. M. Pickett, O. Andersson, Ignition Quality Effects on Lift-Off Stabilization of Synthetic Fuels, SAE International Journal of Engines 8 (2) (2015) 625-634, ISSN 1946-3944, doi: \bibinfo\{doi\}\{10.4271/2015-01-0792\}, URL http://papers.sae.org/ 2015-01-0792/.

[55] J. M. Desantes, V. Bermúdez, J. J. Lopez, D. López-Pintor, Experimental validation of an alternative method to predict high and low-temperature ignition delays under transient thermodynamic conditions for PRF mixtures using a Rapid CompressionExpansion Machine, Energy Conversion and Management 129 (2016) 23-33, ISSN 01968904, doi:\bibinfo\{doi\}\{10.1016/j.enconman. 2016.09.089\}, URL http://linkinghub.elsevier.com/retrieve/ $\mathrm{pii} / \mathrm{S} 0196890416308974$.

[56] Y. Pei, M. Mehl, W. Liu, T. Lu, W. J. Pitz, S. Som, A Multicomponent Blend as a Diesel Fuel Surrogate for Compression Ignition Engine Applications, Journal of Engineering for Gas Turbines and Power 137 (11) (2015) 111502, ISSN 0742-4795, doi: $\backslash$ bibinfo $\{$ doi $\}\{10.1115 / 1$. 4030416\}, URL http://gasturbinespower asmedigitalcollection. asme.org/article. aspx?doi=10.1115/1.4030416. 